\title{
Airway Epithelium Dysfunction in Cystic Fibrosis and COPD
}

\author{
Virginia De Rose $\mathbb{D}^{1},{ }^{1}$ Kevin Molloy $\mathbb{D}^{0}{ }^{2}$ Sophie Gohy, ${ }^{3,4}$ Charles Pilette, ${ }^{3,4}$ \\ and Catherine M. Greene iD ${ }^{5}$ \\ ${ }^{1}$ Department of Clinical and Biological Sciences, University of Torino, A.O.U. S. Luigi Gonzaga, Regione Gonzole 10, 10043 \\ Orbassano, Torino, Italy \\ ${ }^{2}$ Department of Medicine, Royal College of Surgeons in Ireland, Education and Research Centre, Beaumont Hospital, Dublin 9 , \\ Dublin, Ireland \\ ${ }^{3}$ Institute of Experimental and Clinical Research, Pole of Pneumology, ENT and Dermatology, Université Catholique de Louvain \\ (UCL), Brussels, Belgium \\ ${ }^{4}$ Department of Pneumology, Cliniques Universitaires St-Luc, Brussels, Belgium \\ ${ }^{5}$ Lung Biology Group, Department of Clinical Microbiology, Royal College of Surgeons in Ireland, Education and Research Centre, \\ Beaumont Hospital, Dublin 9, Dublin, Ireland
}

Correspondence should be addressed to Virginia De Rose; virginia.derose@unito.it

Received 21 September 2017; Revised 15 January 2018; Accepted 1 February 2018; Published 8 April 2018

Academic Editor: Maria Rosaria Catania

Copyright (C) 2018 Virginia De Rose et al. This is an open access article distributed under the Creative Commons Attribution License, which permits unrestricted use, distribution, and reproduction in any medium, provided the original work is properly cited.

\begin{abstract}
Cystic fibrosis is a genetic disease caused by mutations in the CFTR gene, whereas chronic obstructive pulmonary disease (COPD) is mainly caused by environmental factors (mostly cigarette smoking) on a genetically susceptible background. Although the etiology and pathogenesis of these diseases are different, both are associated with progressive airflow obstruction, airway neutrophilic inflammation, and recurrent exacerbations, suggesting common mechanisms. The airway epithelium plays a crucial role in maintaining normal airway functions. Major molecular and morphologic changes occur in the airway epithelium in both $\mathrm{CF}$ and $\mathrm{COPD}$, and growing evidence suggests that airway epithelial dysfunction is involved in disease initiation and progression in both diseases. Structural and functional abnormalities in both airway and alveolar epithelium have a relevant impact on alteration of host defences, immune/inflammatory response, and the repair process leading to progressive lung damage and impaired lung function. In this review, we address the evidence for a critical role of dysfunctional airway epithelial cells in chronic airway inflammation and remodelling in CF and COPD, highlighting the common mechanisms involved in the epithelial dysfunction as well as the similarities and differences of the two diseases.
\end{abstract}

\section{Introduction}

Cystic fibrosis (CF) is the most common genetic disease in the white population and results from mutations in a single gene encoding for a 1480 residue transmembrane glycoprotein, the cystic fibrosis transmembrane conductance regulator (CFTR). Lung disease, characterized by chronic neutrophilic inflammation, progressive airflow obstruction, and airway bacterial infections, is the major cause of morbidity and mortality in patients with CF $[1,2]$. Chronic obstructive pulmonary disease (COPD) is a major global health problem, and it is estimated to become the third leading cause of death worldwide by 2020 ; the disease is caused by both genetic and environmental factors; among these, cigarette smoking is the main risk factor for COPD and triggers an inflammatory response throughout the airways, in the alveoli, and in the pulmonary vasculature $[3,4]$. The two predominant phenotypes in COPD are emphysema and chronic bronchitis; however, they often overlap in most patients. Although CF and COPD are different in many aspects, they also share key phenotypical and pathologic features suggesting potential mechanistic links (Figure 1). Both diseases are associated with progressive airflow obstruction, chronic neutrophilic inflammation in the airway lumen, and recurrent infectious exacerbations; disease 


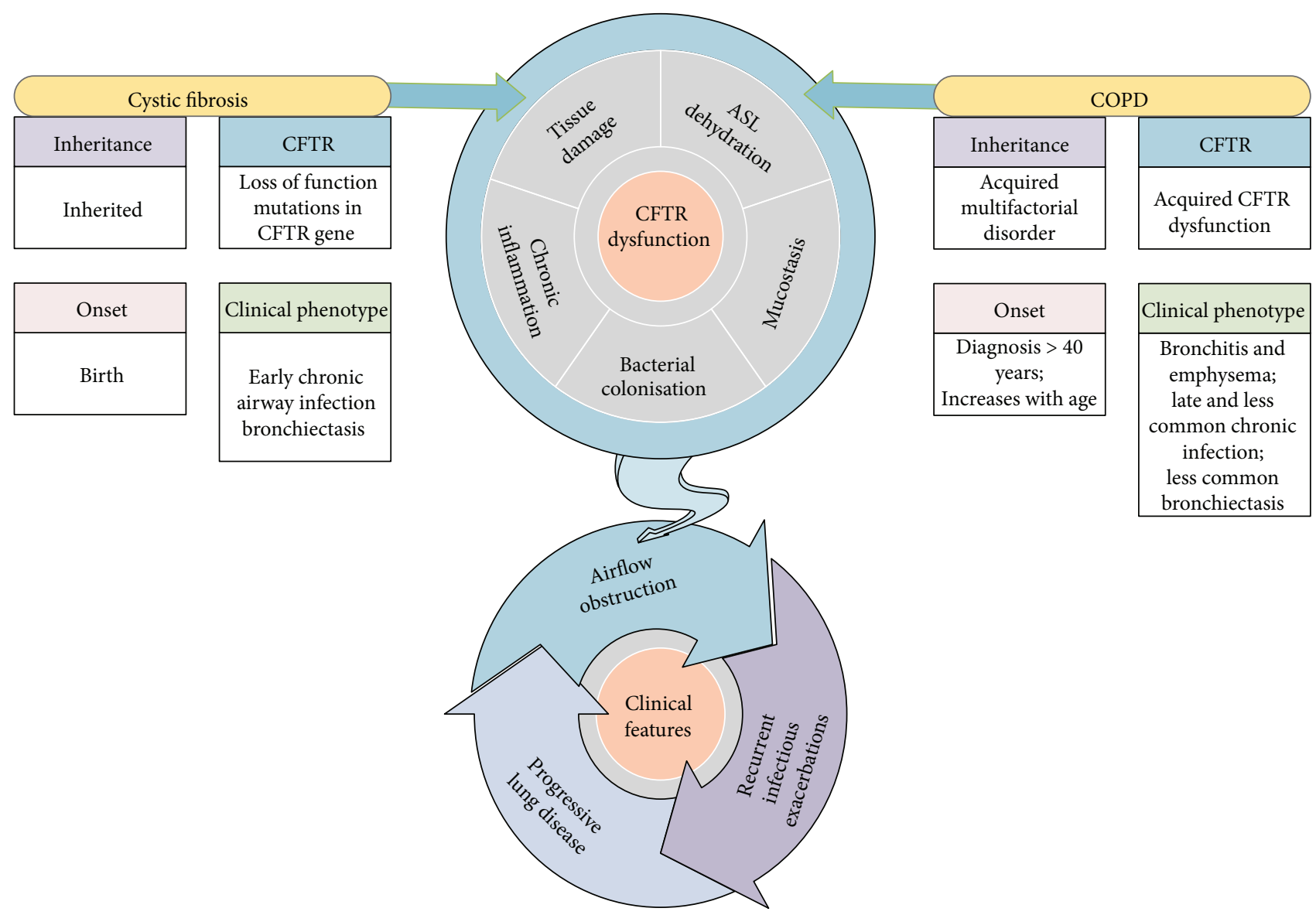

FIGURE 1: Similarities and differences between cystic fibrosis and COPD. Cystic fibrosis (CF) is a genetic disease caused by mutations in the CFTR gene, while COPD is a multifactorial-acquired disease of later onset predominantly associated with cigarette smoke exposure. Although the diseases are different in many aspects, they also share key phenotypical features. Recent evidence suggests that cigarette smoke induces an acquired CFTR dysfunction in COPD and that both CF and COPD have corresponding molecular phenotypes of CFTR dysfunction resulting in airway surface liquid (ASL) dehydration, mucostasis, bacterial colonization, chronic inflammation, and tissue damage. Airflow obstruction, recurrent infective exacerbations, and a progressive decline in lung function characterize both conditions.

exacerbations significantly contribute to morbidity and mortality in both diseases and have a relevant impact on patient's quality of life as well as on health care expenditures [1-4].

Airway epithelial cells (AEC) are among the first sites of contact for inhaled insults and play a crucial role in maintaining normal airway function $[5,6]$. The airway epithelium represents the primary site of relevant molecular and histologic changes in both CF and COPD, and growing evidence in recent years has suggested that it plays a key role in disease initiation and progression in both diseases. Structural and functional changes in both airway and alveolar epithelium have a relevant impact on alteration of the airway milieu, host defences, and the repair processes that contribute to the airflow limitation characteristic of both diseases. The airway epithelium could therefore represent a suitable target for novel therapeutic strategies aiming to restore barrier integrity and defences against inhaled particles and pathogens. In this review, we address the evidence for a critical role of dysfunctional airway epithelium in impaired local defences, altered immune responses, chronic airway inflammation, and remodelling in CF and COPD, highlighting the common mechanisms involved in epithelial dysfunction as well as the similarities and differences of the two diseases.

\section{Properties of Airway Epithelium}

The airway epithelium acts as a physical barrier to prevent potential pathogens or noxious agents entering airway mucosa and reaching the bloodstream [7]. In addition, the airway epithelium controls ion transport to keep the airways hydrated and, furthermore, acts as a key regulator of innate immune responses toward invading pathogens.

2.1. Barrier Function. The crossing of one or multiple host barriers by a pathogen is critical to initiate infection. The airway epithelium provides a physical barrier to microbial invasion; it consists of a monolayer of polarised epithelial cells which maintain their integrity by apical junction complexes (AJC). These consist of occluding tight junctions (TJ), anchoring adherens junctions (AJ), desmosomes, and GAP junctions. 
TJs regulate the movement of ions, macromolecules, and immune cells through the paracellular space; they are critical for ion transport and act as a barrier to regulate the access of inflammatory cells and against the entry of harmful substances such as microbial components into the airway lumen. TJs are constructed from zona occludens proteins ( $\mathrm{ZO}$ ), occludin, claudins, and junctional adhesion molecules (JAMs). AJs mediate cell-cell adhesion and signalling pathways that control cell growth, morphology, and differentiation. They are located below TJs in the lateral membrane and utilise cadherins to mediate calcium-dependent cellular adhesion by binding a cadherin of the same type on an adjacent cell [8]. Gap junctions are not part of AJCs and are pathways of intercellular communication constructed with channel proteins called connexins [9].

2.2. Mucociliary Escalator. The airway is maintained in a constant state of hydration through the coordinated actions of the CFTR channel and amiloride-sensitive epithelial sodium channel $(\mathrm{ENaC})$. The airway surface liquid layer (ASL) comprises a mucus layer which functions to trap particulate matter, bacteria, and viruses, and the underlying periciliary liquid layer (PCL), which provides hydration, enabling effective mucociliary transport and clearance [10]. A finely tuned balance between chloride secretion by CFTR on the one hand and sodium absorption by $\mathrm{ENaC}$ on the other keeps the ASL sufficiently hydrated to permit effective and sustained mucus clearance via the mucociliary escalator; additional ion channels contribute to maintain ASL homeostasis (reviewed in Section 3). Mucus dehydration, defective mucociliary clearance of microbes, infection, and inflammation are the hallmarks of CF and COPD lung disease.

2.3. Pathogen Sensing. The airway epithelium senses pathogens using pattern recognition receptors (PRRs) including Toll-like receptors (TLRs), RIG-I-like receptors (RLRs), Nod-like receptors (NLRs), C-type lectin receptors (CLRs), protease-activated receptors (PARs), and the bitter and sweet taste receptors, amongst others. TLRs are expressed by epithelial cells throughout the respiratory tract including tracheal, bronchial, and alveolar type II cells and respond rapidly to infection or tissue damage by sensing local microbial and host-derived factors (Figure 2(a)). The nucleic acidsensing TLRs (TLR3, TLR7, and TLR9) and the RLRs, RIG-I, and MDA-5 provide defence against viruses invading the respiratory tract [11], by generating IL-6, CXCL8 (IL-8), and IFN- $\beta$ responses. RIG-I and MDA-5 expression is increased in influenza $A$ virus-infected nasal epithelium in a process believed to resist IAV infection [12].

Various NLRs are expressed by airway epithelial cells. NOD1 activation can reduce airway hyperresponsiveness and decrease allergen-specific T-cell proliferation in allergeninduced lung inflammation [13]; its expression is downregulated during pollen season among patients with allergic rhinitis [14]. NLRP3 mediates airway epithelial cell responses to inhaled particulate matter, for example, PM10 [15].

A major function of epithelial CLRs is to sense fungal species, for example, dectin-1, which recognises $\beta$-glucan motifs in Aspergillus fumigatus and house dust mite (HDM)
[16] whereas nonfungal allergens, such as Derp1 and cockroach allergen, which have proteolytic properties, can elicit allergic airway inflammation via PAR-2. Bitter and sweet taste receptors (T2R and T1R, resp.) are G-protein-coupled receptors expressed in respiratory epithelia (reviewed in [17]) that are activated by quorum-sensing molecules such as homoserine lactones from Pseudomonas aeruginosa or sugars. Their activation can enhance mucociliary clearance [18]. In addition, new roles are emerging for other receptors expressed by airway epithelium such as fractalkine receptor CX3CR1 [19] and the short-chain fatty acid receptor GPR41 [20].

In addition to membrane-bound PRRs, in the lung, soluble forms also exist that include mannose-binding lectin (MBL) and surfactant proteins A and D. Ligands for MBL include high mannose and $\mathrm{N}$-acetylglucosamine oligosaccharides that trigger the activation of the classical complement pathway [21]. Surfactant proteins (SP) B and C lower alveolar surface tension whereas SP-A and SP-D bind to macrophages and stimulate their chemotaxis [22] or Gram-negative bacteria and inhibit T-cell proliferation [23], respectively.

2.4. Innate Immunity. The airway epithelium plays a key role in the lung's innate immune responses. Together with the complement system, the antiproteases, antimicrobial peptides, and cytokines expressed by airway epithelial cells or present within the airway lumen represent major factors that function to rid the lungs of infectious or invading microbes and cope with toxic intrapulmonary insults due to pathogens or environmental pollutants.

The complement system opsonizes pathogens and generates chemotactic peptides and the membrane attack complex [24]. Alpha-1 antitrypsin (AAT), secretory leukoprotease inhibitor (SLPI) and elafin are the most abundant serine antiproteases in the lung. Each has important beneficial effects within the lung and their dysregulated activity can adversely impact on the inflammatory process (Figure 2(b)) [25-30].

Antimicrobial peptides form part of the lung's innate immune defences, and inactivation of these peptides has been implicated in airway infections (Figure 2(b)). Lactoferrin is a monomeric iron-binding glycoprotein $(76-80 \mathrm{kDa})$ present in the secondary granules of neutrophils [31]. It plays a microbiostatic role in mucosal fluids [32] and also has antiviral, antifungal, and anticancer activities and can act as an immunomodulator. The primary functions of LL-37 are to eliminate pathogens, inhibit biofilm, and enhance the immune responses [33]. Human beta-defensins are small (4-6 kDa) cationic peptides. Twenty-six human DEFB genes have been identified but only HBD1-4 are secreted by the respiratory tract and play a role in airway mucosal defense. HBDs possess antibacterial [34], antiviral [35], and antifungal properties [36]. HBD-2 and HBD-3 also have immunomodulatory properties [37].

\section{Mucus Production/ASL Regulation in CF and COPD}

As previously described, the airway epithelium is covered by the ASL that comprises a mucus layer and the underlying 


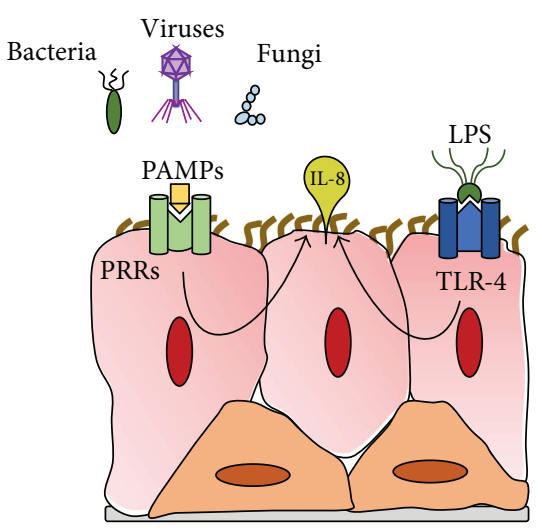

(a)

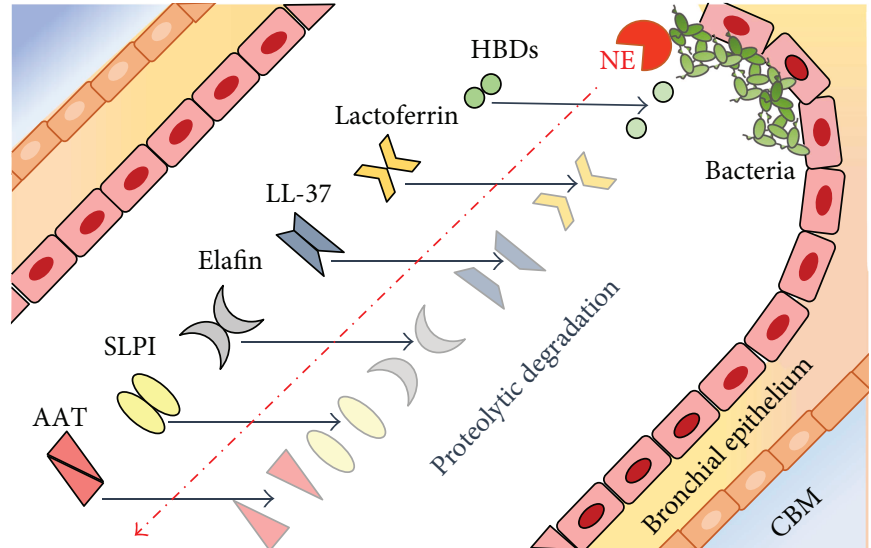

(b)

FIGURE 2: Airway innate immunity. (a) The major pattern recognition receptor (PRR) is the Toll-like receptor (TLR) family which interact with microbial-derived factors or pathogen-associated molecular patterns (PAMPs) such as LPS from P. aeruginosa. LPS-induced activation of TLR induces an IL-8 response via a NF- $\kappa$ B pathway. (b) Important antiproteases and antimicrobial proteins in the lung include AAT, SLPI, elafin, the cathelicidin LL-37, lactoferrin, and the human beta defensins (HBDs); these can be cleaved and inactivated by neutrophil elastase in the CF lung. CBM: capillary basement membrane.

PCL. Airway mucus is responsible for hydration of the epithelium and acts as an essential protective component of the innate defense system of the airways [38, 39]: inhaled microorganisms, noxious agents, and particles get entrapped in mucus and eliminated by mucociliary clearance (MCC) and/or cough, thus protecting the lung from airway infection and inflammation. The two main secreted airway mucins are MUC5AC and MUC5B [38, 40]; the latter but not MUC5AC seems to be required for airway defence against bacteria [41]. Properly hydrated mucus is a critical component of airway homeostasis; failure to maintain adequate mucus hydration, mucus hypersecretion, and altered mucus properties lead to impairment of mucociliary clearance and are prominent features of chronic airway diseases such as CF and COPD, contributing to airway obstruction in these diseases. Ion channels that regulate $\mathrm{Na}^{+}$and $\mathrm{Cl}^{-}$transport are required for the proper hydration and composition of ASL. CFTR is the primary apical ion channel involved in $\mathrm{Cl}^{-}$transport in the lung epithelium; in addition, it is also implicated in the regulation of $\mathrm{ENaC}$ that is rate limiting for $\mathrm{Na}^{+}$and fluid absorption from the airway surface. Additional ion channels in the airway epithelium play a role in maintaining ASL homeostasis, including the solute carrier 26A (SLC26A) family of anion exchangers and calcium-activated chloride channels $[42,43]$. Alterations in ASL composition and disruption of this tightly regulated airway milieu have been linked to the pathogenesis of $\mathrm{CF}$ lung disease and COPD. In CF, the defect/dysfunction of the CFTR protein causes a defect in chloride and bicarbonate transport into the airway lumen that results in dehydration and acidification of ASL, production of viscous, acidic, and altered secretions, with impairment of MCC; this in turn induces airway obstruction, favouring chronic bacterial infection and inflammation (Figure 3). Recent studies showed that the ASL volume depletion causes a collapse of cilia and impairs mucus transport, further supporting the concept that ASL dehydration is a crucial mechanism in CF lung disease [42]. The role of airway surface dehydration as a disease-initiating mechanism is also supported by studies in $\beta \mathrm{ENaC}$ transgenic mice and in SCL26A9 mice [44-48]. Recent biophysical studies provided novel insight on the effects of airway surface dehydration, showing that this leads to an increase of the concentration of secreted mucins and consequently of the osmotic pressure of the mucus layer; when the latter increases above a critical threshold, the PCL and the cilia get compressed leading to stasis and adhesion of mucus on the airway surface [49]. This critical mucus hyperconcentration may be induced not only by the CFTR ion transport defect but also by airway inflammation; thus, it may play an important role in the pathogenesis of chronic inflammatory diseases such as COPD [50].

In addition to airway surface dehydration, the impaired bicarbonate secretion mediated by CFTR dysfunction results in altered mucus structure, increased viscosity and abnormal mucus secretion; therefore, it may contribute to mucus plugging and the impairment of MCC in CF lung disease beyond that caused by airway dehydration alone. Several recent studies support the key role of bicarbonate secretion in regulating local $\mathrm{pH}$ and the airway milieu and in maintaining normal mucus properties: bicarbonate, in fact, drives ionic content and fluids on epithelial surfaces and allows mucins to unfold, and its depletion has been shown to result in dense mucus and increased ASL viscosity thus impairing mucociliary transport [51-53]. Altered ASL viscosity would be a primary CF defect that might contribute, at least in part, to the pathogenesis of CF lung disease. Subsequently, infection, inflammation, and airway remodelling, with their consequences, may further modify ASL viscosity and further enhance the defect of mucociliary transport. Loss of CFTR-mediated bicarbonate secretion has also been shown to inhibit the activity of antimicrobial peptides present in ASL [53]. Thus, dysfunction of CFTR and the subsequent lack of bicarbonate and chloride secretion create an abnormal airway milieu, with impaired innate host defences that favours chronic airway infection and inflammation leading to progressive lung 


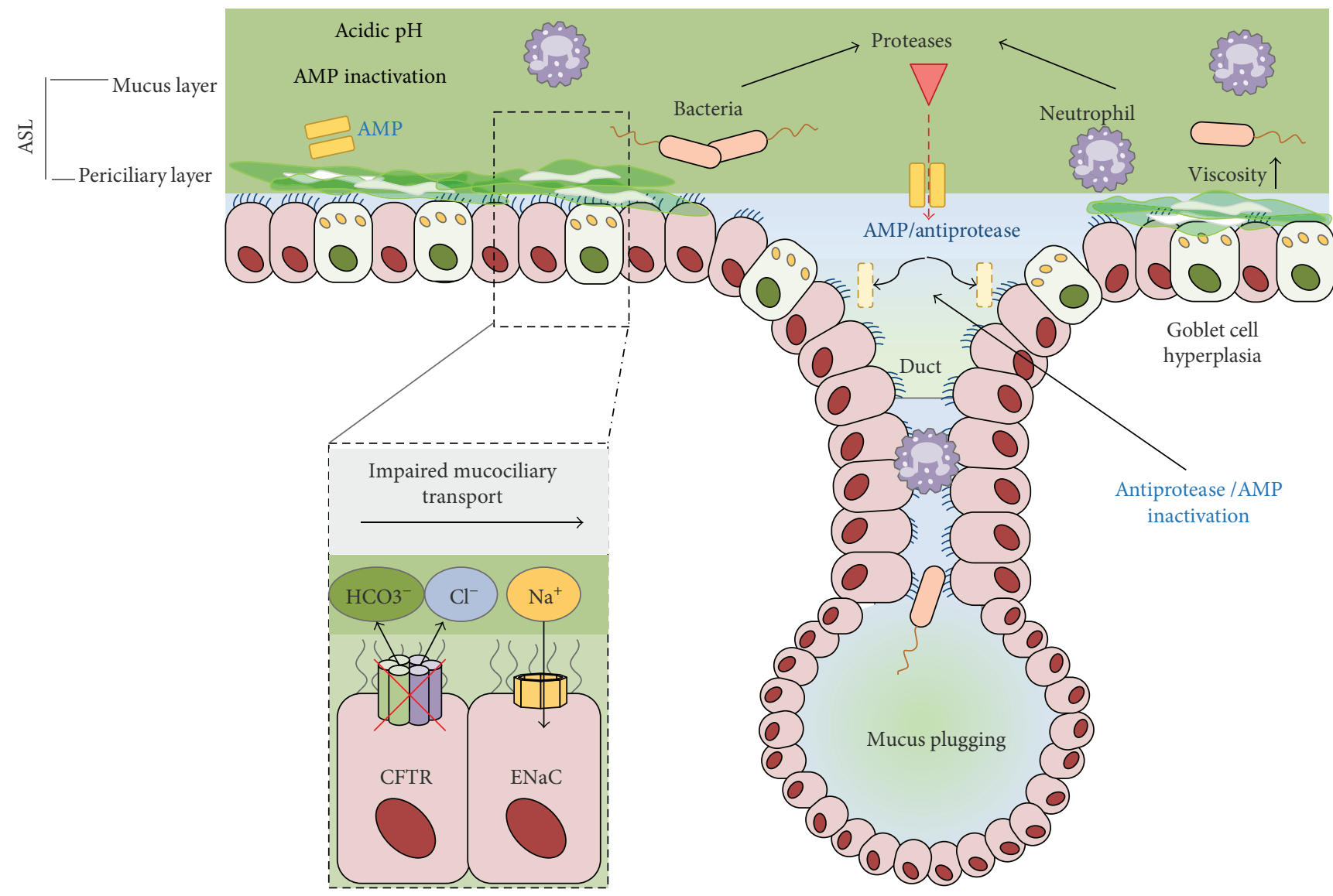

Figure 3: Pathophysiology of airway disease in cystic fibrosis. In cystic fibrosis, loss of normal CFTR function and overactivity of ENaC result in acidification (loss of $\mathrm{HCO}^{-}$secretion) and dehydration of the airway surface liquid layer (ASL) disrupting the normal mucociliary escalator. This results in an increase in ASL viscosity, mucus plugging, bacterial colonization, and neutrophil-dominated inflammation. An overabundance of bacterial and neutrophil derived proteases degrades important antiproteases and antimicrobial peptides in the CF airways further compounding an already-overwhelmed impaired innate immune system.

injury and ultimately to respiratory failure (Figure 3). Furthermore, recently, it has been shown that the loss of CFTR leaves $\mathrm{H}^{+}$secretion by the nongastric $\mathrm{H}^{+} / \mathrm{K}^{+}$adenosine triphosphatase (ATP12A) unchecked, which further decreases the ASL $\mathrm{pH}$ further impairing airway innate host defences [53].

Cigarette smoking is the major risk factor for COPD, a disease that shares some phenotypical features with CF, such as impaired mucociliary clearance, chronic airway inflammation, progressive airflow obstruction, and recurrent bacterial exacerbations. In particular, COPD patients with the chronic bronchitis phenotype exhibit pathologic and clinical features similar to CF, including goblet cell hyperplasia, mucin hyperexpression, and mucus accumulation and hypersecretion that contribute to bacterial infection and subsequent inflammatory responses and have been associated with lung function decline in COPD patients (Figure 1).

Increasing evidence shows that cigarette smoking induces an acquired CFTR dysfunction in patients with normal CFTR gene. Welsh firstly reported that cigarette smoke decreases chloride secretion in the airway epithelium [54]. Several subsequent studies then showed that sustained exposure to cigarette smoke and cigarette smoke extract (CSE) was able to reduce CFTR expression and function in vivo in smokers and in COPD patients and in airway epithelial cells in vitro [55-58]. Several independent mechanisms have been proposed to account for these effects of smoke, including aberrant transcript expression, direct effects of smoke metabolites on CFTR function, and accelerated internalization of CFTR $\mathrm{Cl}^{-}$channels from the apical plasma membrane (Figure 4) [55, 56, 58-61]. Smoke-induced CFTR dysfunction results in ASL dehydration, and it was shown that ASL height decreased permanently after chronic smoke exposure due to changes in active ion transport, indicating an effect of smoke on ASL homeostasis. It has also been shown that CSE is capable of inducing a delayed mucociliary transport in vitro and a marked increase of mucus expression both in vitro and in vivo. CSE has also been shown to be capable of inducing MUC5AC expression and mucus hyperproduction in AEC, an effect that seems to be mediated through ROS-dependent autophagy [62-64]. Together with mucin hypersecretion, smoke-induced CFTR dysfunction will aggravate mucus hyperconcentration and plugging in COPD airways (Figure 4) [42, 65-68]. Tobacco smoke components such as acrolein and acetaldehyde have been shown to impair mucociliary clearance [69]; furthermore, acrolein and 


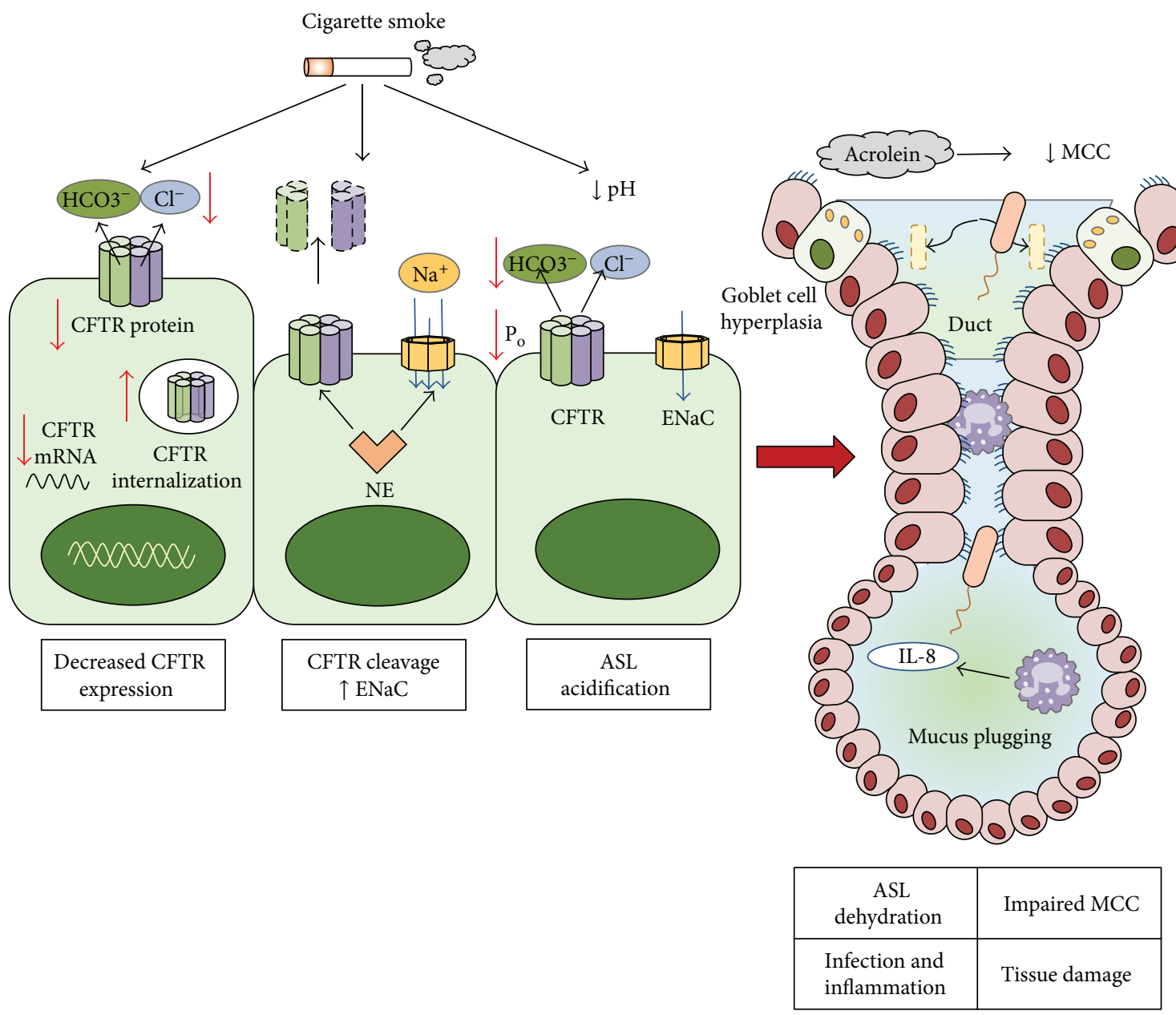

FIGURE 4: Effects of cigarette smoke on CFTR and pathophysiology of airway disease in COPD. Cigarette smoke components (e.g., acrolein and cadmium) can decrease expression and function of the CFTR protein by decreasing CFTR mRNA and protein levels, accelerated CFTR internalization, and decreased channel opening probability $\left(P_{\mathrm{o}}\right)$. Increased levels of neutrophil elastase in COPD may worsen CFTR dysfunction by degrading CFTR and upregulating ENaC expression. Loss of CFTR function results in ASL dehydration and acidification, mucus hypersecretion, and mucus plugging leading to reduced mucociliary clearance, chronic inflammation, impaired innate immunity, and infection.

cadmium inhibit CFTR function in vitro and can reach detectable levels in humans as well (Figure 4) [70, 71].

In ciliated cells from nasal brushing of smoke-exposed subjects and moderate/severe COPD patients, ciliary beat frequency was significantly reduced compared to control subjects $[72,73]$. Furthermore, CS exposure has been shown to affect ciliogenesis and to cause ciliary shortening [74], effects that further contribute to the impairment of MCC.

Reduced MCC leads to accumulation and adhesion of mucus in the airways, favouring retention of irritants and noxious agents contained in cigarette smoke. This in turn triggers exaggerated inflammatory/immune responses, with recruitment of neutrophils and macrophages and excess of protease release that promotes the formation of emphysema in the lungs of smokers with COPD [60, 75]. Recent studies shows that CFTR protein expression correlates inversely with emphysema severity in lungs of COPD patients, suggesting that impaired CFTR function may also be implicated in emphysema formation in humans [76]. A role of CFTR dysfunction in the pathogenesis of emphysema is further supported by studies in $\beta \mathrm{ENaC}$ transgenic mice demonstrating that CF-like airway surface dehydration does cause not only chronic mucus obstruction and airway inflammation but also emphysematous changes in these mice [44, 46, 77]. Interestingly, we demonstrated that genetic deletion and pharmacologic inhibition of PI3K $\gamma$ decreases both neutrophilic airway inflammation and structural lung damage in $\beta \mathrm{ENaC}$ transgenic mice [78].

As previously discussed, defective CFTR also decrease bicarbonate secretion, that is, crucial in $\mathrm{pH}$ ASL regulation and in maintaining normal mucus properties. Tobacco smoke exposure decreases bicarbonate secretion presumably resulting in acidification of ASL and increased ASL viscosity (Figure 4) [42, 79, 80].

A marked decrease of CFTR function has been reported in the upper and lower airways of smokers and patients with COPD; interestingly, in COPD patients, significant correlations have been shown between clinical manifestations such 
as dyspnea and symptoms of chronic bronchitis and the levels of CFTR suppression in their lower airways [56]. The marked oxidant burden and neutrophilic inflammation associated with COPD and particularly with advanced disease further aggravate the effects of CFTR dysfunction in COPD airways. Studies using cell lines expressing wildtype CFTR have shown that a prolonged exposure to oxidant stress with either t-butylhydroquinone or cigarette smoke extract was capable of inhibiting CFTR function, protein levels, and gene expression [55, 81, 82]. Furthermore, it has been reported that CS-induced CFTR dysfunction and the associated inflammatory/oxidative stress cause an impairment of autophagy that also contributes to the development of emphysema [56, 82, 83].

All these data support the concept that CFTR dysfunction caused by cigarette smoke may contribute to the pathophysiology of COPD and may represent a potential target for the development of novel therapeutic approaches.

\section{Innate Immune Response in $\mathrm{CF}$ and COPD Epithelium}

The airway epithelium contributes to host defence by a variety of mechanisms including its barrier function and mucociliary clearance, as well as by the production of antimicrobial peptides and proteins and a range of cytokines, chemokines, and growth factors that mediate leukocyte recruitment, modulation of innate and adaptive immunity, and tissue repair and remodelling [84-86]. Through these mechanisms, the airway epithelium contributes directly to host defence and augments the immune response via the recruitment of inflammatory/immune cells and the interaction with other structural cells in the airway wall.

4.1. Innate Immune Responses in CF Epithelium. A vicious cycle of infection followed by intense neutrophil-dominated inflammation, ineffective clearance of infection, and irreversible airway destruction is characteristic of CF. Airway inflammation is ultimately driven by a dysfunctional epithelium due to an impairment in innate host defence systems, secondary to mutations of CFTR [87-90]. Defective bicarbonate secretion due to CFTR dysfunction reduces ASL pH, impairing the activity of antimicrobial peptides and mucus properties. Despite the ineffectiveness of the CF airway surface to remove mucus, goblet cells are likely to continue secreting mucins [91] leading to plugging. Specific defects in many aspects of the lung's innate immune repertoire are evident in CF.

The CF airway is a TLR agonist-rich environment, and chronic inflammation in CF may for the most part be due to activation of TLRs [92]. Although TLR hyperresponsiveness is largely accepted to contribute to CF lung disease, hyporesponsiveness to TLRs can also negatively impact on pulmonary inflammation. During high circulating oestrogen (E2) states in the female CF airways, a TLR hyporesponsiveness, manifested by reduced IL-8 release, occurs in response to a range of bacterial agonists [93]. A hyporesponsive state may be problematic, leading to ineffective clearing of microorganisms.
NOD1 (or CARD4) and NOD2 (or CARD 15) detect peptidoglycan of Gram-positive or Gram-negative bacteria, and their activation causes induction of proinflammatory NF- $\kappa$ B-dependent cytokines [94]. IL-17 has been shown to augment expression of NOD1, NOD2, and TLR4. By upregulating these PRRs, IL-17 primes the airway to increase its inflammatory response (IL-8) to bacterial ligands. Interestingly, pretreatment of CFTR $\Delta$ F508 cells with IL-17 resulted in a 10-fold increase in IL-8 synthesis following treatment with a NOD1 agonist, highlighting the importance of NOD1 as contributor to aberrant inflammatory responses in the CF lung [95].

Polymorphisms in the mannose-binding lectin 2 (MBL2) promoter can affect MBL serum levels. Relative deficiency of MBL appears to accelerate the age-related decline in lung function in CF patients as MBL-deficient patients older than 15 years of age displayed poorer lung function compared with those younger than 15 years of age [96].

Likewise, relative reduction in SP-A and SP-D has been observed in patients with CF [97] and levels inversely correlate with inflammation and bacterial burden [98]. The cause may be related to the ability of $P$. aeruginosa elastase and protease IV to degrade SP-A and SP-D in the CF lung $[99,100]$. Furthermore, CFTR-dependent alterations in complementmediated interactions between $P$. aeruginosa and monocytes may contribute to enhanced susceptibility to infection in patients with CF [101].

An inherent proinflammatory state exists in the CF airways and may precede bacterial colonization. Overproduction of the neutrophil chemokine IL- 8 by CF airway epithelial cells may be a consequence of both intrinsic CFTR dysfunction [102] and infection [103]. Elevated concentrations of proinflammatory cytokines including TNF- $\alpha$, IL-1, and IL-8 have been found in children with CF [104]. TNF$\alpha$ concentrations in sputum are not significantly correlated with clinical status but do show a strong correlation with sputum IL-8 levels [105].

Interleukin 17 (IL-17-A/F) is a proinflammatory cytokine with roles in the immunopathogenesis of $\mathrm{CF}$ and COPD. Elevated IL-17A mRNA and protein in CF sputum implicate this cytokine in the persistent neutrophilic infiltration in CF lung disease [106]. IL-17 positively regulates the production of proneutrophilic mediators from CF epithelial cells by increasing IL-8 and IL-6 [107]. IL-17A is significantly higher in BALF of symptomatic patients as compared with clinically asymptomatic patients with $\mathrm{CF}$, and its increased concentrations precede infection with microbes such as $P$. aeruginosa and thus have clinical relevance [108].

Antiproteases within the CF lung are susceptible to cleavage and inactivation by host proteases (Figure 2(b)). SLPI is susceptible to cleavage by cathepsins B, L, and S [109] and elafin by NE in lungs of patients colonized with $P$. aeruginosa [110]. Although levels of AAT rise in acute inflammation, in the CF lung, the inhibitory activity of AAT is overwhelmed by an excess of NE.

While lactoferrin has been reported to be present at higher concentrations in the CF lung compared with normal lungs [111], its activity may be suboptimal secondary to cleavage by Pseudomonas elastase and NE [112]. 
Cleavage of lactoferrin by cathepsins B, L, and $\mathrm{S}$ also results in loss of its microbicidal and antibiofilm activity, and in the CF lung, this may potentiate the biofilm forming ability of $P$. aeruginosa [113].

The effectiveness of LL-37 may be hampered in the CF lung through complexing with polymers including GAGs or DNA released from the breakdown of neutrophils and other cells $[114,115]$.

Finally, variant alleles (single-nucleotide polymorphisms) in the DEFB1 gene encoding HBD-1 may contribute to the colonization of $P$. aeruginosa in CF [116]. Beyond that, cysteinyl cathepsins which are present at higher than normal levels in the CF lung cleave and inactivate HBD2 and HBD3 [117].

\subsection{Innate Immune Responses in COPD Epithelium. An} increasing number of studies demonstrate that epithelial defence functions are altered or decreased in chronic airway diseases including COPD and that, as described in $\mathrm{CF}$, defects in the innate immune system play a relevant role also in the pathogenesis and pathophysiology of COPD [5, 42, 118-123]. Cigarette smoke induces relevant alterations in the airway epithelial architecture and impairs epithelial barrier function by increasing the permeability of the airway epithelium, decreasing ciliary function, and reducing mucociliary clearance. This epithelial barrier dysfunction in turn can increase the entry of pathogens and noxious particles into the airway mucosa, further impairing the barrier function and host defences [4, 5, 39, 124, 125-130]. Cigarette smoke induces mucous cell hyperplasia and mucus hypersecretion contributing to airway obstruction; in the small airways, smoking-induced goblet cell hyperplasia is associated with loss of club cells, responsible for the production of secretoglobin, surfactant protein, and other defense factors [131]. A reduced expression of polymeric immunoglobulin receptor/secretory component ( $\mathrm{pIgR/SC}$ ) has also been reported in the COPD epithelium that impairs the transepithelial transport of secretory IgA and correlates with the severity of airflow obstruction [132]. Cigarette smoke may affect epithelial cell functions through a variety of mechanisms, including direct oxidant activity, TLR signalling, ER stress induction, and activation of the integrated stress response $[133,134]$. In addition to impairing barrier function, cigarette smoke exposure increases the release of inflammatory mediators by AEC, whereas it decreases the expression and activity of ASL antimicrobial peptides (AMP). This defect, caused by smoking-induced CFTR dysfunction, is common to CF airways and contributes to the increased susceptibility to respiratory infections shared by both diseases. The antimicrobial activity of AMPs may also be affected by other conditions occurring in both CF and COPD airways such as AMP degradation by microbial and host proteases and AMP inhibition by microbial polysaccharides, F-actin, and DNA from dying cells. Cigarette smoke also inhibits the molecular pathways involved in interferon production in response to viral infections [135]. Whereas the expression and activity of epithelial AMP are impaired in COPD, the levels of neutrophil-derived peptides and LL37 are increased as a consequence of the marked neutrophilic inflammation in this disease and further increase during disease exacerbations [136-145]. Likewise, increased levels of lysozyme and lactoferrin have been reported in BALF of patients with COPD [121, 146], whereas SLPI levels were reported to be increased in stable patients, but decreased during disease exacerbations [144, 147, 148]. However, some inconsistent findings concerning sputum AMP levels in COPD patients have been reported in previous studies $[136-139,149]$ that may be due to the small sample sizes of these studies and the different clinical conditions and disease stage of patients.

Exposure to cigarette smoke also leads to activation of several PRRs, either directly by components of smoke or indirectly by causing injury to epithelial cells $[84,121,134$, $150,151]$. As in CF, also in COPD, TLR4 has been suggested to play a key role in the inflammatory/immune response: TLR4-defective mice show attenuated lung inflammation after challenge with cigarette smoke [152-154]. Elevated levels of damage-associated molecular patterns (DAMPs), such as high-mobility group box 1 (HMGB1) [155], uric acid, and extracellular ATP [156], have been observed in the BALF of patients with COPD compared with smokers without COPD. Extracellular ATP has been shown to activate the NLRP3 inflammasome, regulating the expression of interleukin- $\beta$ and IL-18, [153] particularly during disease exacerbations [157, 158]. In IL-1R knock-out mice, pulmonary inflammation induced by acute exposure to cigarette smoke was attenuated and these mice were protected against emphysema after chronic smoke exposure [159].

Activation of AEC by cigarette smoke or pathogens also triggers an inflammatory response, with the release of cytokines and chemokines such as TNF- $\alpha$, IL-1, IL-6, GM-CSF, and IL- 8 acting on inflammatory/immune cells as well as on resident cells $[5,84,85,119,121,134,150,152,158]$.

Similar to what occurs in CF airways, activated AEC from COPD patients release more IL- 8 than cells from smoking control subjects [160] and display a proinflammatory phenotype in culture [161], although the molecular mechanisms are different in CF and COPD. Levels of IL-17 and other Th17 cytokines are also increased in sputum and airways of patients with COPD as reported in $\mathrm{CF}$, further enhancing neutrophil recruitment. [162, 163]. Whereas physiologically the inflammatory process induces protective immune responses, in patients with $\mathrm{COPD}$ and $\mathrm{CF}$, chronic airway inflammation amplifies the tissue damage and further impairs local immune defences, thus contributing to susceptibility to recurrent infections. Neutrophils and alveolar macrophages are increased and activated in COPD, as well as in the CF lung, and contribute to the oxidant burden and the protease/antiprotease imbalance that drive the development of emphysematous changes in both diseases. Furthermore, neutrophils from COPD patients show altered chemotactic responses [164] that impair their defence function whereas macrophages show reduced phagocytic ability [165-167] and impaired innate responses to respiratory pathogens. These alterations facilitate the chronic colonization of the airways and infectious exacerbations [168]. An increased number and activation of dendritic cells in the lung of patients with COPD have also been reported in some studies that seem to correlate with disease severity [169-171], 
whereas other studies have found decreased numbers of these cells and an impaired maturation status [172-175]. Recent studies suggest that innate lymphoid cells (ILC), with important roles in immune homeostasis and lung immunity, may play a role in COPD [176-178]. In mice exposed to cigarette smoke, a strong type 1 response to influenza virus was observed that was associated with a transdifferentiation of ILC2 into ILC1 cells, induced by IL-12 and IL-18 [178]; in patients with COPD, an increase of ILC1 and a decrease of ILC2 cells was reported in lung tissue [178, 179]. Finally, recently, it has also been reported that pulmonary natural cytotoxicity receptor- (NCR-) ILC3 cells tend to accumulate into the lungs of COPD patients [177]; these cells produce IL-17A and IL-22 and might contribute to driving neutrophilic inflammation in the COPD airways. Interestingly, these cytokines are also crucial in the formation of lymphoid follicles [180, 181], the numbers of which are increased around the small airways and in the lung parenchyma [182-184] in severe COPD as well as in peribronchial, parenchymal, and perivascular areas in the lung of CF patients with advanced lung disease [185]. The peribronchial localization of tertiary lymphoid organs and the epithelial expression of IL17A and chemokines involved in their development suggest a role for airway epithelium in lymphoid neogenesis in these diseases. However, differently from COPD, a shift from $\mathrm{B}$ cell to T-cell predominance has been observed in CF lymphoid follicles, suggesting that the cellular adaptive immune response is specifically affected in CF [185]. Recently, Frija-Masson and colleagues [186] showed that peribronchial lymphoid neogenesis was induced in the lungs of mice upon persistent bacterial infection, suggesting that chronic bacterial infection contributes to the lymphoid neogenesis observed in both COPD and CF.

A growing body of evidence now suggests that dysfunction of epithelial innate immune responses and the consequent chronic airway inflammation can drive the initiation, exacerbation, and progression of chronic inflammatory disease such as COPD and CF. In this context, therapeutic targeting of dysfunctional immune responses could be an interesting strategy in the treatment of these diseases.

\section{Comparison of Epithelial Remodelling in CF and COPD}

Efficient epithelial regeneration following injury is crucial in tissue homeostasis and prevention of disease. Exposure to repeated noxious/inflammatory stimuli as well as airway epithelial dysfunction affects epithelial regeneration and repair pathways and the ability of epithelial cells to restore barrier functions; this leads to aberrant remodelling and structural damage that further impair epithelial functions and generate a vicious cycle favouring aggressions by potential exogenous insults.

Both CF and COPD are characterized by dysfunctional airway epithelial repair and remodelling that impair lung architecture and contribute to disease pathogenesis and progression.

In $\mathrm{CF}$, progressive remodelling of the airways ultimately results in structural damage with development of bronchiectasis, emphysema, and impaired lung function. Differently from COPD, structural changes of the airway and alveolar wall in CF appear early in life. There is still debate about the sequence of events leading to remodelling and structural alterations in $\mathrm{CF}$ and their relationship to infection and inflammation; in particular, it is still debated whether structural changes are related to and initiated by infection/inflammation or are a result of CFTR dysfunction independent of infection and inflammation [87-90, 102104]. Hyperplasia of goblet cells and basal cells [187-190], squamous metaplasia [187, 190, 191], increased epithelial height [187, 192], cell shedding [187-190, 193], with loss of ciliated epithelial cells, and a disorganization of tight junctions and compound cilia [192, 194-196] have been reported in the context of epithelial remodelling in CF airways; extensive structural changes of the small airway epithelia have also been observed, including epithelial shedding and altered barrier integrity [197]. Conflicting results have been reported concerning epithelial and reticular basement membrane (RBM) in adult patients that was found thickened in some studies [189, 198, 199], but significantly thinner than normal in other studies [200]. Interestingly, many of these structural changes are similar to those observed in COPD, although the molecular mechanisms initiating these changes are different.

Whereas until recently, little was known about the frequency of occurrence and the clinical relevance of emphysematous changes in CF lung disease, recent studies show that, with the remarkable increase of patient survival, emphysema is now a more prominent disease component in CF. Using quantitative CT measurements, Wielpütz and colleagues [201] showed that early onset and progressive emphysema is a characteristic feature of CF lung disease; emphysema is observed in early adolescence, increases in adult CF patients, correlates with lung function, and contributes to disease severity. Mets and colleagues [202] pathologically and radiologically confirmed that emphysema is common in advanced CF lung disease, is related to age, and in some cases approaches the changes observed in explanted lungs of COPD patients. Thus, emphysema might become an increasingly important disease component in the aging $\mathrm{CF}$ population. Several mechanisms mainly related to CFTR dysfunction may induce emphysema formation in CF patients; among these, chronic inflammation with protease/ antiprotease imbalance and extracellular matrix proteolysis, altered ceramide metabolism, alveolar apoptosis, and defective autophagy $[63,76,203]$. Most of these mechanisms are common to those involved in the pathogenesis of smokeinduced emphysema.

Some studies have reported that CFTR plays an important role in regulating the early events of epithelial cell migration $[188,198,200]$ and that CF airway epithelial cells exhibit slower migration and wound repair than non-CF cells $[188,198,204]$. The findings that the pharmacological rescue of CFTR function in CF cells significantly improved wound healing and that inhibition of CFTR expression or activity decreased proliferation and migration of nonCF airway epithelial cells $[188,198]$ further support the role of CFTR in modulating airway epithelial cell 
migration and the concept of a dysfunctional airway epithelium in CF. Data obtained on tissues from CF fetuses (taken at autopsy) or in a humanized nude mouse xenograft model and in CF mice suggest that the epithelial remodelling starts to occur prenatally and in the absence of infection [205-207]. A recent in vitro study, using CF human airway epithelial cell cultures, confirmed and extended these findings, showing that CF epithelium regeneration, even in the absence of exogenous infection/ inflammation, was abnormal and associated with basal cell hyperplasia and with delayed ciliated cell differentiation. The findings of this study demonstrate that the abnormal remodelling in CF epithelium was partly induced by the intrinsic hyperinflammatory phenotype of CF cells [208]. Interestingly, in this study, an increase in $\mathrm{CF}$ epithelium height was observed in the context of epithelium remodelling. An increased epithelium height was previously reported in vivo in CF lungs as compared with lungs from COPD patients [192] and in these latter patients as compared with non-COPD subjects at both the nasal and bronchial levels [209]. Similarly, basal cell hyperplasia, a finding associated with increased epithelium height, was also reported in vivo in CF $[187,189]$ and COPD lungs [210]. It has been already emphasized that chronic inflammation is a hallmark of CF; inflammation begins early in the disease even in the apparent absence of infection, and it has been postulated that it may be dysregulated in the $\mathrm{CF}$ lung as a consequence of defective CFTR [87-90, 102-104, $211,212]$. Interestingly, stimulation of non-CF airway epithelial cells with proinflammatory cytokines mimicked the abnormal remodelling observed in CF epithelial cells and induced an increase of epithelium height and basal cell numbers comparable to those observed in CF cultures [208]. Overall, the findings of the previous studies suggest that exogenous infection and inflammation are not the exclusive factors affecting airway epithelium remodelling in $\mathrm{CF}$ and that the intrinsic dysfunction of CF airway epithelial cells plays an important role in this process and in the alterations of epithelial regeneration following injury. A growing number of in vitro and in vivo studies support the notion that chronic neutrophilic inflammation is a key factor in structural lung damage and lung function decline in CF through the release of damaging neutrophil products such as $\mathrm{NE}$ and reactive oxidant species $[211,212]$. Airway inflammation is further augmented after onset of chronic airway infection. A vicious cycle of neutrophilic inflammation, noxious mediator release, and overwhelmed defences occurs within the airways that further exacerbates epithelial injury and remodelling, leading to disease progression and irreversible lung damage. The chronic neutrophilic inflammation, heightened during acute exacerbations of the disease, is a common process in CF and COPD and may be involved in the common abnormalities observed in vivo in remodelled airway epithelium, as well as in the destructive alterations of airway and alveolar walls.

There is evidence of degradation of structural components of the extracellular matrix (ECM) such as elastin, collagen, and glycosaminoglycans in the CF lung; these alterations are associated with the marked and early protease/ antiprotease imbalance, with the release of high quantities of matrix metalloproteases (MMP), NE, and other proteases that contribute to the tissue damage and development of bronchiectasis and emphysema [213-216]. There is increasing evidence that the high levels of free NE activity observed in sputum and BALF from CF patients not only are able to cleave a number of ECM proteins but have also other direct and indirect deleterious effects on the epithelial repair process: in fact, they significantly impact the adhesion, proliferation, and wound repair of primary AEC [217]. There is also considerable in vivo evidence of an imbalance of MMP and their inhibitors (tissue inhibitors of MMP, TIMPs) in the $\mathrm{CF}$ airways with prevalence and activation of MMP [214, 218-221]. Activation of MMP-7 has been shown to inactivate AAT, thus further augmenting the effect of free $\mathrm{NE}$ activity [221], whereas the release and activation of MMP12 is involved in alveolar wall destruction [63]. A recent proteomic study of CF AEC showed significantly increased secretion of ECM proteins fibronectin, laminin, perlecan, and galectin-3 [222], whereas the CFTR defect was associated with a decreased integrin $\beta 1$ signaling and a reduced wound repair [223]. These studies further support a role of mutant CFTR protein in the abnormal migration and reparative properties of the $\mathrm{CF}$ epithelium. Fibrotic changes associated with small airway narrowing have also been described, in particular in end-stage CF [224-226]. A recent study, using micro CT and histology documented dilatation and obstruction of distal airways and a severe reduction in the number of functional terminal bronchioles in end-stage CF lungs, confirming that, similar to COPD, obstruction and remodelling of peripheral airways are a prominent feature in CF lung disease [226].

Similar to CF, the airway epithelium represents a primary site of relevant molecular and morphologic changes in COPD; structural modifications of the epithelium in COPD resemble that observed in CF and include basal cell hyperplasia, squamous metaplasia, goblet cell hyperplasia, decreased integrity of the apical junctional barrier, and epithelial shedding [132, 222, 227]. Moreover, a reduction of cilia length and ciliary beating have been observed in COPD and upon cigarette smoke exposure [72, 127]; altered function and/or number of ciliated and goblet cells impair mucociliary clearance, contributing to the development of airway obstruction similar to what occurs in CF. Although pathologic changes in COPD lungs involve both the airways and parenchyma, studies by Hogg and colleagues clearly showed that smoking-induced changes in the small airways are crucial in the development of airway obstruction in COPD and precede destruction of the alveolar structure [228], similar to what was observed in CF. Interestingly, recently, it has been reported that smoking is able to induce a distal-to-proximal reprogramming of the small airway epithelium in COPD lungs, with a shift toward the proximal airway epithelial phenotype. These changes represent a novel feature of small airway pathology in COPD and seem to be mediated by exaggerated epidermal growth factor/epidermal growth factor receptor signaling in small airway epithelium basal cells [229]. An increased expression of epithelial growth factor receptors 
has been described in AEC of COPD patients, which might contribute to squamous metaplasia and an increased risk of bronchial carcinoma [230].

Normal differentiation of epithelial cells in COPD is altered both in terms of cellular functions and of the polarity of the epithelial cells, notably through epithelial to mesenchymal transition (EMT). This leads to dysfunctional physical, chemical, and immune barrier functions; whilst aberrant repair and remodelling of the COPD epithelium further impair epithelial functions. Cigarette smoke increases epithelial permeability by disassembly of tight junction proteins via the epidermal growth factor receptor pathway [124]. This may favour viral, fungal, and bacterial translocation through the epithelium.

As described for CF AEC, Perotin et al. recently showed that wound repair is delayed in primary cultures of severe and very severe COPD [231]. The epithelial cells undergoing EMT lose their epithelial phenotype, become able to migrate along and through the basement membrane, and presumably participate to peribronchial fibrosis [232]. EMT is reported both in upper airways (in chronic sinusitis) $[233,234]$ and in small and large lower airways in COPD [235] and is induced by cigarette smoke and by TGF- $\beta$ [236, 237]. Cigarette smoke also promotes Wnt signaling: Heijink and colleagues reported that cigarette smoke increases Wnt-5B expression in COPD AEC cultures and favours a mesenchymal phenotype through a mechanism involving TGF- $\beta$ / Smad-3 [238]. More recently, Baarsma and colleagues showed an enhanced expression of noncanonical Wnt-5A in experimental models of COPD and in human COPD that functionally impaired canonical Wnt signal-driven alveolar epithelial cell repair [239]. Overall, these findings suggest that alterations in Wnt signalling may contribute to abnormal repair and remodelling in COPD. As already highlighted, a reduced expression of the epithelial pIgR has also been reported in COPD that impairs the transepithelial transport of secretory $\operatorname{IgA}[132,240,241]$. Interestingly, a recent study shows that pIgR-deficient mice develop COPD-like airway and parenchymal remodelling, resulting from persistent activation of inflammatory signalling by an altered lung microbiome, thus suggesting that S-IgA deficiency may play a role in small airway remodelling and disease progression in COPD [242] These findings are consistent with the results of previous studies showing that reduced $\mathrm{pIgR}$ expression in COPD epithelium correlates with the severity of airflow obstruction in this disease [241].

The dedifferentiation of the COPD epithelium through aberrant regenerating mechanisms is responsible for an altered physical, chemical, and immune response to inhaled particles and microbes. Furthermore, epithelial cell activation by cigarette smoke and other inhaled irritants in COPD induces the release of inflammatory mediators, further enhancing chronic airway inflammation. All these events can increase airway epithelial damage and promote an excess of extracellular matrix deposition and airway fibrosis, driving disease progression in COPD [158]. Restoration of the epithelial integrity by targeting signalling pathways involved in aberrant repair and remodelling is promising but will need further research $[243,244]$.

\section{Conclusions and Therapeutic Perspectives}

Cystic fibrosis is a genetic disease caused by mutations in the CFTR gene, whereas COPD is mainly caused by environmental factors-mostly cigarette smoking-on a genetically susceptible background [1-4]. Although the etiology and pathophysiology of these diseases are different, they share key phenotypical features such as chronic neutrophilic inflammation, progressive airflow obstruction, and recurrent infectious exacerbations, suggesting the possibility of common mechanisms. In particular, COPD patients with the chronic bronchitis phenotype exhibit pathologic and clinical features similar to $\mathrm{CF}$, including goblet cell hyperplasia, mucin hyperexpression, mucus accumulation, and hypersecretion that contribute to bacterial infection and subsequent inflammatory responses, and have been associated with lung function decline in COPD patients. Growing evidence suggests that cigarette smoking induces an acquired CFTR dysfunction in patients with COPD, reducing the expression and/or function of the protein, and that this CFTR dysfunction is involved in most of the pathogenetic pathways common to both COPD and CF.

Airway epithelial cells are among the first sites of contact for pathogens and other noxious environmental irritants and play a critical role in maintaining normal airway functions and the homeostasis of the airway milieu. Relevant molecular and morphologic changes occur in the airway epithelium in both CF and COPD, similar in some aspects, and a growing body of evidence suggests that airway epithelial dysfunction is involved in disease initiation and progression in both diseases. Structural and functional abnormalities in both airway and alveolar epithelium have a relevant impact on alteration of host defences, immune/ inflammatory responses, and the repair processes, leading to progressive lung damage and facilitating chronic and recurrent airway infections in both $\mathrm{CF}$ and COPD.

An increasing number of studies show that CFTR dysfunction affects several physiological processes relevant to airway epithelial cell functions, including chloride and bicarbonate transport, mucin secretion and MCC, host defences, and inflammatory/immune responses. Thus, CFTR dysfunction represents a potential target for the development of novel therapeutic approaches. An improved understanding of the common mechanisms affected by CFTR dysfunction in CF and COPD and the relevance of CFTR dysfunction in the different COPD phenotypes would provide new insights into disease pathogenesis and will be important for developing novel therapeutic strategies relevant to both diseases. Recently, innovative and specific therapies targeting the CFTR defect have been developed; in the context of the increasing evidence about the role of CFTR dysfunction in COPD, the possibility that therapies designed to correct the CFTR dysfunction may benefit not only CF patients but also patients with COPD is attractive and need further studies.

\section{Conflicts of Interest}

All authors declare that there is no conflict of interests regarding the publication of this paper. 


\section{References}

[1] F. Ratjen and G. Döring, "Cystic fibrosis," The Lancet, vol. 361, no. 9358, pp. 681-689, 2003.

[2] J. S. Elborn, "Cystic fibrosis," The Lancet, vol. 388, no. 10059, pp. 2519-2531, 2016.

[3] M. Decramer, W. Janssens, and M. Miravitlles, "Chronic obstructive pulmonary disease," The Lancet, vol. 379, no. 9823, pp. 1341-1351, 2012.

[4] P. J. Barnes, P. G. J. Burney, E. K. Silverman et al., "Chronic obstructive pulmonary disease," Nature Reviews Disease Primers, vol. 1, article 15076, 2015.

[5] W. Gao, L. Li, Y. Wang et al., "Bronchial epithelial cells: the key effector cells in the pathogenesis of chronic obstructive pulmonary disease?," Respirology, vol. 20, no. 5, pp. 722-729, 2015.

[6] A. Tam, S. Wadsworth, D. Dorscheid, S. F. P. Man, and D. D. Sin, "The airway epithelium: more than just a structural barrier," Therapeutic Advances in Respiratory Disease, vol. 5, no. 4, pp. 255-273, 2011.

[7] S. Ganesan, A. T. Comstock, and U. S. Sajjan, "Barrier function of airway tract epithelium," Tissue Barriers, vol. 1, no. 4, article e24997, 2013.

[8] M. Goodwin and A. S. Yap, "Classical cadherin adhesion molecules: coordinating cell adhesion, signaling and the cytoskeleton," Journal of Molecular Histology, vol. 35, no. 8-9, pp. 839-844, 2004.

[9] Q. Wang and B. Margolis, "Apical junctional complexes and cell polarity," Kidney International, vol. 72, no. 12, pp. 14481458, 2007.

[10] E. N. Worthington and R. Tarran, "Methods for ASL measurements and mucus transport rates in cell cultures," Methods in Molecular Biology, vol. 742, pp. 77-92, 2011.

[11] L. Tengroth, C. R. Millrud, A. M. Kvarnhammar, S. Kumlien Georén, L. Latif, and L. O. Cardell, "Functional effects of tolllike receptor (TLR)3, 7, 9, RIG-I and MDA-5 stimulation in nasal epithelial cells," PLoS One, vol. 9, no. 6, article e98239, 2014.

[12] H. J. Kim, C.-H. Kim, M.-J. Kim et al., "The induction of pattern-recognition receptor expression against influenza a virus through Duox2-derived reactive oxygen species in nasal mucosa," American Journal of Respiratory Cell and Molecular Biology, vol. 53, no. 4, pp. 525-535, 2015.

[13] C. Tabeling, H. Scheer, S. M. Schönrock et al., "Nucleotide oligomerization domain 1 ligation suppressed murine allergen-specific T-cell proliferation and airway hyperresponsiveness," American Journal of Respiratory Cell and Molecular Biology, vol. 50, no. 5, pp. 903-911, 2014.

[14] J. Bogefors, C. Rydberg, R. Uddman et al., "Nod1, Nod2 and Nalp3 receptors, new potential targets in treatment of allergic rhinitis?," Allergy, vol. 65, no. 10, pp. 1222-1226, 2010.

[15] J. A. Hirota, M. J. Gold, P. R. Hiebert et al., "The nucleotidebinding domain, leucine-rich repeat protein 3 inflammasome/IL-1 receptor I axis mediates innate, but not adaptive, immune responses after exposure to particulate matter under $10 \mu \mathrm{m}, "$ American Journal of Respiratory Cell and Molecular Biology, vol. 52, no. 1, pp. 96-105, 2015.

[16] A. T. Nathan, E. A. Peterson, J. Chakir, and M. Wills-Karp, "Innate immune responses of airway epithelium to house dust mite are mediated through $\beta$-glucan-dependent pathways," Journal of Allergy and Clinical Immunology, vol. 123, no. 3, pp. 612-618, 2009.

[17] B. Mirković, M. A. Murray, G. M. Lavelle et al., "The role of short-chain fatty acids, produced by anaerobic bacteria, in the cystic fibrosis airway," American Journal of Respiratory and Critical Care Medicine, vol. 192, no. 11, pp. 1314-1324, 2015.

[18] R. J. Lee and N. A. Cohen, "Bitter and sweet taste receptors in the respiratory epithelium in health and disease," Journal of Molecular Medicine, vol. 92, no. 12, pp. 1235-1244, 2014.

[19] R. J. Lee and N. A. Cohen, "The emerging role of the bitter taste receptor T2R38 in upper respiratory infection and chronic rhinosinusitis," American Journal of Rhinology \& Allergy, vol. 27, no. 4, pp. 283-286, 2013.

[20] T. Chirkova, S. Lin, A. G. P. Oomens et al., "CX3CR1 is an important surface molecule for respiratory syncytial virus infection in human airway epithelial cells," Journal of General Virology, vol. 96, no. 9, pp. 2543-2556, 2015.

[21] M. W. Turner, "Mannose-binding lectin (MBL) in health and disease," Immunobiology, vol. 199, no. 2, pp. 327-339, 1998.

[22] J. R. Wright and D. C. Youmans, "Pulmonary surfactant protein a stimulates chemotaxis of alveolar macrophage," American Journal of Physiology-Lung Cellular and Molecular Physiology, vol. 264, no. 4, pp. L338-L344, 1993.

[23] P. J. Borron, E. A. Mostaghel, C. Doyle, E. S. Walsh, M. G. McHeyzer-Williams, and J. R. Wright, "Pulmonary surfactant proteins $\mathrm{A}$ and $\mathrm{D}$ directly suppress $\mathrm{CD}^{+} / \mathrm{CD}^{+}$cell function: evidence for two shared mechanisms," The Journal of Immunology, vol. 169, no. 10, pp. 5844-5850, 2002.

[24] P. H. Pandya and D. S. Wilkes, "Complement system in lung disease," American Journal of Respiratory Cell and Molecular Biology, vol. 51, no. 4, pp. 467-473, 2014.

[25] C. M. Greene, S. J. Marciniak, J. Teckman et al., " $\alpha 1$-Antitrypsin deficiency," Nature Reviews Disease Primers, vol. 2, article 16051, 2016.

[26] R. C. Thompson and K. Ohlsson, "Isolation, properties, and complete amino acid sequence of human secretory leukocyte protease inhibitor, a potent inhibitor of leukocyte elastase," Proceedings of the National Academy of Sciences, vol. 83, no. 18 , pp. 6692-6696, 1986.

[27] O. Wiedow, J. Harder, J. Bartels, V. Streit, and E. Christophers, "Antileukoprotease in human skin: an antibiotic peptide constitutively produced by keratinocytes," Biochemical and Biophysical Research Communications, vol. 248, no. 3, pp. 904-909, 1998.

[28] J. M. Sallenave and A. Silva, "Characterization and gene sequence of the precursor of elafin, an elastase-specific inhibitor in bronchial secretions," American Journal of Respiratory Cell and Molecular Biology, vol. 8, no. 4, pp. 439-445, 1993.

[29] J. W. McMichael, A. Roghanian, L. Jiang, R. Ramage, and J.M. Sallenave, "The antimicrobial antiproteinase elafin binds to lipopolysaccharide and modulates macrophage responses," American Journal of Respiratory Cell and Molecular Biology, vol. 32, no. 5, pp. 443-452, 2005.

[30] K. Baranger, M. L. Zani, J. Chandenier, S. Dallet-Choisy, and T. Moreau, "The antibacterial and antifungal properties of trappin-2 (pre-elafin) do not depend on Its protease inhibitory function," FEBS Journal, vol. 275, no. 9, pp. 2008-20, 2008 . 
[31] T. Ganz, "Antimicrobial polypeptides in host defense of the respiratory tract," Journal of Clinical Investigation, vol. 109, no. 6, pp. 693-697, 2002.

[32] A. O. Qamruddin, M. A. Alkawash, and J. S. Soothill, "Antibiotic susceptibility of Stenotrophomonas maltophilia in the presence of lactoferrin," Antimicrobial Agents and Chemotherapy, vol. 49, no. 10, pp. 4425-4426, 2005.

[33] O. E. Sørensen, P. Follin, A. H. Johnsen et al., "Human cathelicidin, hCAP-18, is processed to the antimicrobial peptide LL-37 by extracellular cleavage with proteinase 3," Blood, vol. 97, no. 12, pp. 3951-3959, 2001.

[34] J.-R. C. García, A. Krause, S. Schulz et al., "Human $\beta$-defensin 4: a novel inducible peptide with a specific salt-sensitive spectrum of antimicrobial activity," The FASEB Journal, vol. 15, no. 10, pp. 1819-1821, 2001.

[35] Z. Feng, G. R. Dubyak, M. M. Lederman, and A. Weinberg, "Cutting edge: human $\beta$ defensin 3-a novel antagonist of the HIV-1 coreceptor CXCR4," The Journal of Immunology, vol. 177, no. 2, pp. 782-786, 2006.

[36] J. Tomalka, E. Azodi, H. P. Narra et al., “ $\beta$-Defensin 1 plays a role in acute mucosal defense against Candida albicans," The Journal of Immunology, vol. 194, no. 4, pp. 17881795, 2015.

[37] F. Niyonsaba, H. Ogawa, and I. Nagaoka, "Human $\beta$-defensin-2 functions as a chemotactic agent for tumour necrosis factor- $\alpha$-treated human neutrophils," Immunology, vol. 111, no. 3, pp. 273-281, 2004.

[38] J. V. Fahy and B. F. Dickey, "Airway mucus function and dysfunction," New England Journal of Medicine, vol. 363, no. 23, pp. 2233-2247, 2010.

[39] C. Martin, J. Frija-Masson, and P.-R. Burgel, "Targeting mucus hypersecretion: new therapeutic opportunities for COPD?," Drugs, vol. 74, no. 10, pp. 1073-1089, 2014.

[40] M. C. Rose and J. A. Voynow, "Respiratory tract mucin genes and mucin glycoproteins in health and disease," Physiological Reviews, vol. 86, no. 1, pp. 245-278, 2006.

[41] M. G. Roy, A. Livraghi-Butrico, A. A. Fletcher et al., "Muc5b is required for airway defence," Nature, vol. 505, no. 7483, pp. 412-416, 2014.

[42] A. Ghosh, R. C. Boucher, and R. Tarran, "Airway hydration and COPD," Cellular and Molecular Life Sciences, vol. 72, no. 19, pp. 3637-3652, 2015.

[43] S. Blouquit-Laye and T. Chinet, "Ion and liquid transport across the bronchiolar epithelium," Respiratory Physiology \& Neurobiology, vol. 159, no. 3, pp. 278-282, 2007.

[44] M. Mall, B. R. Grubb, J. R. Harkema, W. K. O'Neal, and R. C. Boucher, "Increased airway epithelial $\mathrm{Na}^{+}$absorption produces cystic fibrosis-like lung disease in mice," Nature Medicine, vol. 10, no. 5, pp. 487-493, 2004.

[45] Z. Zhou, J. Duerr, B. Johannesson et al., "The ENaCoverexpressing mouse as a model of cystic fibrosis lung disease," Journal of Cystic Fibrosis, vol. 10, no. 2, pp. S172-S182, 2011.

[46] M. A. Mall, J. R. Harkema,J. B. Trojanek et al., "Development of chronic bronchitis and emphysema in $\beta$-epithelial $\mathrm{Na}^{+}$channel-overexpressing mice," American Journal of Respiratory and Critical Care Medicine, vol. 177, no. 7, pp. 730-742, 2008.

[47] P. Anagnostopoulou, B. Riederer, J. Duerr et al., "SLC26A9mediated chloride secretion prevents mucus obstruction in airway inflammation," Journal of Clinical Investigation, vol. 122, no. 10, pp. 3629-3634, 2012.
[48] S. Gehrig, J. Duerr, M. Weitnauer et al., "Lack of neutrophil elastase reduces inflammation, mucus hypersecretion, and emphysema, but not mucus obstruction, in mice with cystic fibrosis-like lung disease," American Journal of Respiratory and Critical Care Medicine, vol. 189, no. 9, pp. 1082-1092, 2014.

[49] B. Button, L. H. Cai, C. Ehre et al., "A periciliary brush promotes the lung health by separating the mucus layer from airway epithelia," Science, vol. 337, no. 6097, pp. 937-941, 2012.

[50] N. Derichs, B. J. Jin, Y. Song, W. E. Finkbeiner, and A. S. Verkman, "Hyperviscous airway periciliary and mucous liquid layers in cystic fibrosis measured by confocal fluorescence photobleaching," The FASEB Journal, vol. 25, no. 7, pp. 23252332, 2011.

[51] X. X. Tang, L. S. Ostedgaard, M. J. Hoegger et al., "Acidic pH increases airway surface liquid viscosity in cystic fibrosis," Journal of Clinical Investigation, vol. 126, no. 3, pp. 879891, 2016.

[52] A. A. Pezzulo, X. X. Tang, M. J. Hoegger et al., "Reduced airway surface $\mathrm{pH}$ impairs bacterial killing in the porcine cystic fibrosis lung," Nature, vol. 487, no. 7405, pp. 109-113, 2012.

[53] V. S. Shah, D. K. Meyerholz, X. X. Tang et al., "Airway acidification initiates host defense abnormalities in cystic fibrosis mice," Science, vol. 351, no. 6272, pp. 503-507, 2016.

[54] M. J. Welsh, "Cigarette smoke inhibition of ion transport in canine tracheal epithelium," Journal of Clinical Investigation, vol. 71, no. 6, pp. 1614-1623, 1983.

[55] A. M. Cantin, J. W. Hanrahan, G. Bilodeau et al., "Cystic fibrosis transmembrane conductance regulator function is suppressed in cigarette smokers," American Journal of Respiratory and Critical Care Medicine, vol. 173, no. 10, pp. 11391144, 2006.

[56] M. T. Dransfield, A. M. Wilhelm, B. Flanagan et al., "Acquired cystic fibrosis transmembrane conductance regulator dysfunction in the lower airways in COPD," Chest, vol. 144, no. 2, pp. 498-506, 2013.

[57] J. L. Kreindler, A. D. Jackson, P. A. Kemp, R. J. Bridges, and H. Danahay, "Inhibition of chloride secretion in human bronchial epithelial cells by cigarette smoke extract," American Journal of Physiology-Lung Cellular and Molecular Physiology, vol. 288, no. 5, pp. L894-L902, 2005.

[58] L. A. Clunes, C. M. Davies, R. D. Coakley et al., "Cigarette smoke exposure induces CFTR internalization and insolubility, leading to airway surface liquid dehydration," The FASEB Journal, vol. 26, no. 2, pp. 533-545, 2012.

[59] P. A. Sloane, S. Shastry, A. Wilhelm et al., "A pharmacologic approach to acquired cystic fibrosis transmembrane conductance regulator dysfunction in smoking related lung disease," PLoS One, vol. 7, no. 6, p. e39809, 2012.

[60] M. A. Mall, "Unplugging mucus in cystic fibrosis and chronic obstructive pulmonary disease," Annals of the American Thoracic Society, vol. 13, Supplement 2, pp. S177-S185, 2016.

[61] J. E. Rasmussen, J. T. Sheridan, W. Polk, C. M. Davies, and R. Tarran, "Cigarette smoke-induced $\mathrm{Ca}^{2+}$ release leads to cystic fibrosis transmembrane conductance regulator (CFTR) dysfunction," Journal of Biological Chemistry, vol. 289, no. 11, pp. 7671-7681, 2014.

[62] E. Gensch, M. Gallup, A. Sucher et al., "Tobacco smoke control of mucin production in lung cells requires oxygen radicals AP-1 and JNK," Journal of Biological Chemistry, vol. 279, no. 37, pp. 39085-39093, 2004. 
[63] Y. A. Mebratu, K. Schwalm, K. R. Smith, M. Schuyler, and Y. Tesfaigzi, "Cigarette smoke suppresses Bik to cause epithelial cell hyperplasia and mucous cell metaplasia," American Journal of Respiratory and Critical Care Medicine, vol. 183, no. 11, pp. 1531-1538, 2011.

[64] J. S. Zhou, Y. Zhao, H. B. Zhou et al., “Autophagy plays an essential role in cigarette smoke-induced expression of MUC5AC in airway epithelium," American Journal of Physiology-Lung Cellular and Molecular Physiology, vol. 310, no. 11, pp. L1042-L1052, 2016.

[65] S. J. Coles, L. R. Levine, and L. Reid, "Hypersecretion of mucus glycoproteins in rat airways induced by tobacco smoke," American Journal of Pathology, vol. 94, no. 3, pp. 459-472, 1979.

[66] D. Lamb and L. Reid, "Goblet cell increase in rat bronchial epithelium after exposure to cigarette and cigar tobacco smoke," BMJ, vol. 1, no. 5635, pp. 33-35, 1969.

[67] C. Basbaum, H. Lemjabbar, M. Longphre, D. Li, E. Gensch, and N. McNamara, "Control of mucin transcription by diverse injury-induced signaling pathways," American Journal of Respiratory and Critical Care Medicine, vol. 160, Supplement_1, pp. S44-S48, 1999.

[68] M. A. Mall and D. Hartl, "CFTR: cystic fibrosis and beyond," European Respiratory Journal, vol. 44, no. 4, pp. 1042-1054, 2014.

[69] J. A. Dye and K. B. Adler, "Effects of cigarette smoke on epithelial cells of the respiratory tract," Thorax, vol. 49 , no. 8 , pp. 825-834, 1994.

[70] J. Rennolds, S. Butler, K. Maloney et al., "Cadmium regulates the expression of the CFTR chloride channel in human airway epithelial cells," Toxicological Sciences, vol. 116, no. 1, pp. 349-358, 2010.

[71] S. V. Raju, P. L. Jackson, C. A. Courville et al., "Cigarette smoke induces systemic defects in cystic fibrosis transmembrane conductance regulator function," American Journal of Respiratory and Critical Care Medicine, vol. 188, no. 11, pp. 1321-1330, 2013.

[72] A. Yaghi, A. Zaman, G. Cox, and M. B. Dolovich, "Ciliary beating is depressed in nasal cilia from chronic obstructive pulmonary disease subjects," Respiratory Medicine, vol. 106, no. 8, pp. 1139-1147, 2012.

[73] A. M. Agius, L. A. Smallman, and A. L. Pahor, "Age, smoking and nasal ciliary beat frequency," Clinical Otolaryngology and Allied Sciences, vol. 23, no. 3, pp. 227-230, 1998.

[74] E. Tamashiro, G. Xiong, W. T. Anselmo-Lima, J. L. Kreindler, J. N. Palmer, and N. A. Cohen, "Cigarette smoke exposure impairs respiratory epithelial ciliogenesis," American Journal of Rhinology \& Allergy, vol. 23, no. 2, pp. 117-122, 2009.

[75] Z. Zhou-Suckow, J. Duerr, M. Hagner, R. Agrawal, and M. A. Mall, "Airway mucus, inflammation and remodeling: emerging links in the pathogenesis of chronic lung diseases," Cell and Tissue Research, vol. 367, no. 3, pp. 537-550, 2017.

[76] M. Bodas, T. Min, S. Mazur, and N. Vij, "Critical modifier role of membrane-cystic fibrosis transmembrane conductance regulator-dependent ceramide signaling in lung injury and emphysema," The Journal of Immunology, vol. 186, no. 1, pp. 602-613, 2011.

[77] M. O. Wielpütz, M. Eichinger, Z. Zhou et al., "In vivo monitoring of cystic fibrosis-like lung disease in mice by volumetric computed tomography," European Respiratory Journal, vol. 38, no. 5, pp. 1060-1070, 2011.
[78] M. Galluzzo, E. Ciraolo, M. Lucattelli et al., "Genetic deletion and pharmacological inhibition of $\mathrm{PI} 3 \mathrm{~K} \gamma$ reduces neutrophilic airway inflammation and lung damage in mice with cystic fibrosis-like lung disease," Mediators of Inflammation, vol. 2015, Article ID 545417, 10 pages, 2015.

[79] S. T. Ballard, L. Trout, Z. Bebök, E. J. Sorscher, and A. Crews, "CFTR involvement in chloride, bicarbonate, and liquid secretion by airway submucosal glands," American Journal of Physiology-Lung Cellular and Molecular Physiology, vol. 277, no. 4, pp. L694-L699, 1999.

[80] M. J. Hug, T. Tamada, and R. J. Bridges, "CFTR and bicarbonate secretion to epithelial cells," Physiology, vol. 18, no. 1, pp. 38-42, 2003.

[81] A. M. Cantin, G. Bilodeau, C. Ouellet, J. Liao, and J. W. Hanrahan, "Oxidant stress suppresses CFTR expression," American Journal of Physiology-Cell Physiology, vol. 290, no. 1, pp. C262-C270, 2006.

[82] A. M. Cantin, "Cystic fibrosis transmembrane conductance regulator. Implications in cystic fibrosis and chronic obstructive pulmonary disease," Annals of the American Thoracic Society, Supplement 2, pp. S150-S155, 2016.

[83] M. Bodas, D. Silverberg, K. Walworth, K. Brucia, and N. Vij, "Augmentation of S-nitrosoglutathione controls cigarette smoke-induced inflammatory-oxidative stress and chronic obstructive pulmonary disease-emphysema pathogenesis by restoring cystic fibrosis transmembrane conductance regulator function," Antioxidants \& Redox Signaling, vol. 27, no. 7, pp. 433-451, 2017.

[84] P. S. Hiemstra, P. B. McCray Jr, and R. Bals, "The innate immune function of airway epithelial cells in inflammatory lung disease," European Respiratory Journal, vol. 45, no. 4, pp. 1150-1162, 2015.

[85] R. Bals and P. S. Hiemstra, "Innate immunity in the lung: how epithelial cells fight against respiratory pathogens," European Respiratory Journal, vol. 23, no. 2, pp. 327-333, 2004.

[86] D. Parker and A. Prince, "Innate immunity in the respiratory epithelium," American Journal of Respiratory Cell and Molecular Biology, vol. 45, no. 2, pp. 189-201, 2011.

[87] A. M. Cantin, D. Hartl, M. W. Konstan, and J. F. Chmiel, "Inflammation in cystic fibrosis lung disease: pathogenesis and therapy," Journal of Cystic Fibrosis, vol. 14, no. 4, pp. 419-430, 2015.

[88] D. Nichols, J. Chmiel, and M. Berger, "Chronic inflammation in the cystic fibrosis lung: alterations in inter- and intracellular signaling," Clinical Reviews in Allergy \& Immunology, vol. 34, no. 2, pp. 146-162, 2008.

[89] V. De Rose, "Mechanisms and markers of airway inflammation in cystic fibrosis," European Respiratory Journal, vol. 19, no. 2, pp. 333-340, 2002.

[90] M. Cohen-Cymberknoh, E. Kerem, T. Ferkol, and A. Elizur, "Airway inflammation in cystic fibrosis: molecular mechanisms and clinical implications," Thorax, vol. 68, no. 12, pp. 1157-1162, 2013.

[91] J. A. Voynow and B. K. Rubin, "Mucins, mucus, and sputum," Chest, vol. 135, no. 2, pp. 505-512, 2009.

[92] C. M. Greene, T. P. Carroll, S. G. J. Smith et al., "TLR-induced inflammation in cystic fibrosis and non-cystic fibrosis airway epithelial cells," The Journal of Immunology, vol. 174, no. 3, pp. 1638-1646, 2005.

[93] S. H. Chotirmall, C. M. Greene, I. K. Oglesby et al., “ $17 \beta$ estradiol inhibits IL-8 in cystic fibrosis by up-regulating 
secretory leucoprotease inhibitor," American Journal of Respiratory and Critical Care Medicine, vol. 182, no. 1, pp. 62-72, 2010.

[94] E. Voss, J. Wehkamp, K. Wehkamp, E. F. Stange, J. M. Schroder, and J. Harder, "NOD2/CARD15 mediates induction of the antimicrobial peptide human beta-defensin-2," Journal of Biological Chemistry, vol. 281, no. 4, pp. 2005-2011, 2006.

[95] L. Roussel and S. Rousseau, "IL-17 primes airway epithelial cells lacking functional cystic fibrosis transmembrane conductance regulator (CFTR) to increase NOD1 responses," Biochemical and Biophysical Research Communications, vol. 391, no. 1, pp. 505-509, 2010.

[96] M. S. Muhlebach, S. L. MacDonald, B. Button et al., "Association between mannan-binding lectin and impaired lung function in cystic fibrosis may be age-dependent," Clinical and Experimental Immunology, vol. 145, no. 2, pp. 302-307, 2006.

[97] A. D. Postle, A. Mander, K. B. M. Reid et al., "Deficient hydrophilic lung surfactant proteins A and D with normal surfactant phospholipid molecular species in cystic fibrosis," American Journal of Respiratory Cell and Molecular Biology, vol. 20, no. 1, pp. 90-98, 1999.

[98] T. L. Noah, P. C. Murphy, J. J. Alink et al., "Bronchoalveolar lavage fluid surfactant protein-A and surfactant protein-D are inversely related to inflammation in early cystic fibrosis," American Journal of Respiratory and Critical Care Medicine, vol. 168, no. 6, pp. 685-691, 2003.

[99] J. F. Alcorn and J. R. Wright, "Degradation of pulmonary surfactant protein $\mathrm{D}$ by Pseudomonas aeruginosa elastase abrogates innate immune function," Journal of Biological Chemistry, vol. 279, no. 29, pp. 30871-30879, 2004.

[100] J. L. Malloy, R. A. W. Veldhuizen, B. A. Thibodeaux, R. J. O'Callaghan, and J. R. Wright, "Pseudomonas aeruginosa protease IV degrades surfactant proteins and inhibits surfactant host defense and biophysical functions," American Journal of Physiology-Lung Cellular and Molecular Physiology, vol. 288, no. 2, pp. L409-L418, 2005.

[101] P. B. Van de Weert-van Leeuwen, M. A. Van Meegen, J. J. Speirs et al., "Optimal complement-mediated phagocytosis of Pseudomonas aeruginosa by monocytes is cystic fibrosis transmembrane conductance regulatordependent," American Journal of Respiratory Cell and Molecular Biology, vol. 49, no. 3, pp. 463-470, 2013.

[102] O. Tabary, J. M. Zahm, J. Hinnrasky et al., "Selective upregulation of chemokine IL-8 expression in cystic fibrosis bronchial gland cells in vivo and in vitro," The American Journal of Pathology, vol. 153, no. 3, pp. 921-930, 1998.

[103] M. Tsuchiya, P. Kumar, S. Bhattacharyya et al., "Differential regulation of inflammation by inflammatory mediators in cystic fibrosis lung epithelial cells," Journal of Interferon \& Cytokine Research, vol. 33, no. 3, pp. 121-129, 2013.

[104] E. Osika, J. M. Cavaillon, K. Chadelat et al., "Distinct sputum cytokine profiles in cystic fibrosis and other chronic inflammatory airway disease," European Respiratory Journal, vol. 14, no. 2, pp. 339-346, 1999.

[105] P. S. Salva, N. A. Doyle, L. Graham, H. Eigen, and C. M. Doerschuk, "TNF- $\alpha$, IL-8, soluble ICAM-1, and neutrophils in sputum of cystic fibrosis patients," Pediatric Pulmonology, vol. 21, no. 1, pp. 11-19, 1996.

[106] A. Decraene, A. Willems-Widyastuti, A. Kasran, K. De Boeck, D. M. Bullens, and L. J. Dupont, "Elevated expression of both mRNA and protein levels of IL-17A in sputum of stable cystic fibrosis patients," Respiratory Research, vol. 11, no. 1,2010

[107] M. Brodlie, M. C. McKean, G. E. Johnson et al., "Raised interleukin-17 is immunolocalised to neutrophils in cystic fibrosis lung disease," European Respiratory Journal, vol. 37, no. 6, pp. 1378-1385, 2011.

[108] K. Tiringer, A. Treis, P. Fucik et al., "A Th17- and Th2skewed cytokine profile in cystic fibrosis lungs represents a potential risk factor for Pseudomonas aeruginosa infection," American Journal of Respiratory and Critical Care Medicine, vol. 187, no. 6, pp. 621-629, 2013.

[109] C. C. Taggart, G. J. Lowe, C. M. Greene et al., "Cathepsin B, L, and $S$ cleave and inactivate secretory leucoprotease inhibitor," Journal of Biological Chemistry, vol. 276, no. 36, pp. 33345-33352, 2001.

[110] N. Guyot, M. W. Butler, P. McNally et al., "Elafin, an elastasespecific inhibitor, is cleaved by its cognate enzyme neutrophil elastase in sputum from individuals with cystic fibrosis," Journal of Biological Chemistry, vol. 283, no. 47, pp. 3237732385, 2008.

[111] P. Valenti, A. Catizone, F. Pantanella et al., "Lactoferrin decreases inflammatory response by cystic fibrosis bronchial cells invaded with Burkholderia cenocepacia iron-modulated biofilm," International Journal of Immunopathology and Pharmacology, vol. 24, no. 4, pp. 1057-1068, 2011.

[112] B. E. Britigan, M. B. Hayek, B. N. Doebbeling, and R. B. Fick $\mathrm{Jr}$, "Transferrin and lactoferrin undergo proteolytic cleavage in the Pseudomonas aeruginosa-infected lungs of patients with cystic fibrosis," Infection and Immunity, vol. 61, no. 12, pp. 5049-5055, 1993.

[113] M. P. Rogan, C. C. Taggart, C. M. Greene, P. G. Murphy, S. J. O’Neill, and N. G. McElvaney, "Loss of microbicidal activity and increased formation of biofilm due to decreased lactoferrin activity in patients with cystic fibrosis," The Journal of Infectious Diseases, vol. 190, no. 7, pp. 1245-1253, 2004.

[114] G. Bergsson, E. P. Reeves, P. McNally et al., "LL-37 complexation with glycosaminoglycans in cystic fibrosis lungs inhibits antimicrobial activity, which can be restored by hypertonic saline," The Journal of Immunology, vol. 183, no. 1, pp. 543-551, 2009.

[115] D. J. Weiner, R. Bucki, and P. A. Janmey, "The antimicrobial activity of the cathelicidin LL37 is inhibited by F-actin bundles and restored by gelsolin," American Journal of Respiratory Cell and Molecular Biology, vol. 28, no. 6, pp. 738-745, 2003.

[116] R. Tesse, F. Cardinale, T. Santostasi et al., "Association of $\beta$-defensin-1 gene polymorphisms with Pseudomonas aeruginosa airway colonization in cystic fibrosis," Genes \& Immunity, vol. 9, no. 1, pp. 57-60, 2008.

[117] C. C. Taggart, C. M. Greene, S. G. Smith et al., "Inactivation of human $\beta$-defensins 2 and 3 by elastolytic cathepsins," The Journal of Immunology, vol. 171, no. 2, pp. 931-937, 2003.

[118] T. Yoshida and R. M. Tuder, "Pathobiology of cigarette smoke-induced chronic obstructive pulmonary disease," Physiological Reviews, vol. 87, no. 3, pp. 1047-1082, 2007.

[119] P. J. Barnes, "Immunology of asthma and chronic obstructive pulmonary disease," Nature Reviews Immunology, vol. 8, no. 3, pp. 183-192, 2008.

[120] R. Shaykhiev and R. G. Crystal, "Early events in the pathogenesis of chronic obstructive pulmonary disease. Smoking- 
induced reprogramming of airway epithelial basal progenitor cells," Annals of the American Thoracic Society, vol. 11, Supplement 5, pp. S252-S258, 2014.

[121] S. T. Gohy, C. Hupin, C. Pilette, and M. Z. Ladjemi, "Chronic inflammatory airway diseases: the central role of the epithelium revisited," Clinical \& Experimental Allergy, vol. 46, no. 4, pp. 529-542, 2016.

[122] J. C. Hogg and W. Timens, "The pathology of chronic obstructive pulmonary disease," Annual Review of Pathology: Mechanisms of Disease, vol. 4, no. 1, pp. 435-459, 2009.

[123] F. Hassan, X. Xu, G. Nuovo et al., "Accumulation of metals in GOLD4 COPD lungs is associated with decreased CFTR levels," Respiratory Research, vol. 15, no. 1, p. 69, 2014.

[124] I. H. Heijink, S. M. Brandenburg, D. S. Postma, and A. J. M. van Oosterhout, "Cigarette smoke impairs airway epithelial barrier function and cell-cell contact recovery," European Respiratory Journal, vol. 39, no. 2, pp. 419-428, 2012.

[125] R. Shaykhiev, F. Otaki, P. Bonsu et al., "Cigarette smoking reprograms apical junctional complex molecular architecture in the human airway epithelium in vivo," Cellular and Molecular Life Sciences, vol. 68, no. 5, pp. 877-892, 2011.

[126] J. Milara, T. Peiró, A. Serrano, and J. Cortijo, "Epithelial to mesenchymal transition is increased in patients with COPD and induced by cigarette smoke," Thorax, vol. 68, no. 5, pp. 410-420, 2013.

[127] P. L. Leopold, M. J. O’Mahony, X. Julie Lian, A. E. Tilley, B.G. Harvey, and R. G. Crystal, "Smoking is associated with shortened airway cilia," PLOS ONE, vol. 4, no. 12, article e8157, 2009.

[128] S. M. Kennedy, R. K. Elwood, B. J. Wiggs, P. D. Paré, and J. C. Hogg, "Increased airway mucosal permeability of smokers: relationship to airway reactivity," American Review of Respiratory Disease, vol. 129, no. 1, pp. 143-148, 1984.

[129] J. Hessel, J. Heldrich, J. Fuller et al., "Intraflagellar transport gene expression associated with short cilia in smoking and COPD," PLoS One, vol. 9, no. 1, article e85453, 2014.

[130] E. J. Peters, R. Morice, S. E. Benner et al., "Squamous metaplasia of the bronchial mucosa and its relationship to smoking," Chest, vol. 103, no. 5, pp. 1429-1432, 1993.

[131] A. B. Lumsden, A. McLean, and D. Lamb, "Goblet and Clara cells of human distal airways: evidence for smoking induced changes in their numbers," Thorax, vol. 39, no. 11, pp. 844849, 1984.

[132] V. V. Polosukhin, J. M. Cates, W. E. Lawson et al., "Bronchial secretory immunoglobulin a deficiency correlates with airway inflammation and progression of chronic obstructive pulmonary disease," American Journal of Respiratory and Critical Care Medicine, vol. 184, no. 3, pp. 317-327, 2011.

[133] T. Nyunoya, Y. Mebratu, A. Contreras, M. Delgado, H. S. Chand, and Y. Tesfaigzi, "Molecular processes that drive cigarette smoke-induced epithelial cell fate of the lung," American Journal of Respiratory Cell and Molecular Biology, vol. 50, no. 3, pp. 471-482, 2014

[134] M. J. Holtzman, D. E. Byers, J. Alexander-Brett, and X. Wang, "The role of airway epithelial cells and innate immune cells in chronic respiratory disease," Nature Reviews Immunology, vol. 14, no. 10, pp. 686-698, 2014.

[135] U. S. Sajjan, "Susceptibility to viral infections in chronic obstructive pulmonary disease: role of epithelial cells," Current Opinion in Pulmonary Medicine, vol. 19, no. 2, pp. 125-132, 2013.
[136] M. Golec, C. Reichel, B. Mackiewicz et al., "Cathelicidin LL37, granzymes, TGF-beta1 and cytokines levels in induced sputum from farmers with and without COPD," Annals of Agricultural and Environmental Medicine, vol. 16, no. 2, pp. 289-297, 2009.

[137] Y. Y. Jiang, W. Xiao, M. X. Zhu et al., "The effect of human antibacterial peptide LL-37 in the pathogenesis of chronic obstructive pulmonary disease," Respiratory Medicine, vol. 106, no. 12, pp. 1680-1689, 2012.

[138] W. Xiao, Y. P. Hsu, A. Ishizaka, T. Kirikae, and R. B. Moss, "Sputum cathelicidin, urokinase plasminogen activation system components, and cytokines discriminate cystic fibrosis, COPD, and asthma inflammation," Chest, vol. 128, no. 4, pp. 2316-2326, 2005.

[139] M. Tsoumakidou, I. Bouloukaki, K. Thimaki, N. Tzanakis, and N. M. Siafakas, "Innate immunity proteins in chronic obstructive pulmonary disease and idiopathic pulmonary fibrosis," Experimental Lung Research, vol. 36, no. 6, pp. 373-380, 2010.

[140] G. I. Parameswaran, S. Sethi, and T. F. Murphy, "Effects of bacterial infection on airway antimicrobial peptides and proteins in COPD," Chest, vol. 140, no. 3, pp. 611-617, 2011.

[141] G. Paone, V. Conti, A. Vestri et al., "Analysis of sputum markers in the evaluation of lung inflammation and functional impairment in symptomatic smokers and COPD patients," Disease Markers, vol. 31, no. 2, pp. 91-100, 2011.

[142] D. Merkel, W. Rist, P. Seither, A. Weith, and M. . C. Lenter, "Proteomic study of human bronchoalveolar lavage fluids from smokers with chronic obstructive pulmonary disease by combining surface-enhanced laser desorption/ionizationmass spectrometry profiling with mass spectrometric protein identification," Proteomics, vol. 5, no. 11, pp. 2972-2980, 2005.

[143] C. I.-U. Chen, S. Schaller-Bals, K. P. Paul, U. Wahn, and R. Bals, " $\beta$-defensins and LL-37 in bronchoalveolar lavage fluid of patients with cystic fibrosis," Journal of Cystic Fibrosis, vol. 3, no. 1, pp. 45-50, 2004.

[144] L. J. P. Persson, M. Aanerud, J. A. Hardie et al., "Antimicrobial peptide levels are linked to airway inflammation, bacterial colonisation and exacerbations in chronic obstructive pulmonary disease," European Respiratory Journal, vol. 49, no. 3, article 1601328, 2017.

[145] P. Mallia, J. Footitt, R. Sotero et al., "Rhinovirus infection induces degradation of antimicrobial peptides and secondary bacterial infection in chronic obstructive pulmonary disease," American Journal of Respiratory and Critical Care Medicine, vol. 186, no. 11, pp. 1117-1124, 2012.

[146] A. B. Thompson, T. Bohling, F. Payvandi, and S. I. Rennard, "Lower respiratory tract lactoferrin and lysozyme arise primarily in the airways and are elevated in association with chronic bronchitis," The Journal of Laboratory and Clinical Medicine, vol. 115, no. 2, pp. 148-158, 1990.

[147] B. L. Luo, R. C. Niu, J. T. Feng, C. P. Hu, X. Y. Xie, and L. J. $\mathrm{Ma}$, "Downregulation of secretory leukocyte proteinase inhibitor in chronic obstructive lung disease: the role of TGF- $\beta /$ Smads signaling pathways," Archives of Medical Research, vol. 39, no. 4, pp. 388-396, 2008.

[148] C. Hollander, B. Sitkauskiene, R. Sakalauskas, U. Westin, and S. M. Janciauskiene, "Serum and bronchial lavage fluid concentrations of IL-8, SLPI, sCD14 and sICAM-1 in patients 
with COPD and asthma," Respiratory Medicine, vol. 101, no. 9, pp. 1947-1953, 2007.

[149] E. Pace, A. Giarratano, M. Ferraro et al., "TLR4 upregulation underpins airway neutrophilia in smokers with chronic obstructive pulmonary disease and acute respiratory failure," Human Immunology, vol. 72, no. 1, pp. 54-62, 2011.

[150] P. J. Barnes, S. D. Shapiro, and R. A. Pauwels, "Chronic obstructive pulmonary disease: molecular and cellular mechanisms," European Respiratory Journal, vol. 22, no. 4, pp. 672-688, 2003.

[151] A. A. Lugade, P. N. Bogner, T. H. Thatcher, P. J. Sime, R. P. Phipps, and Y. Thanavala, "Cigarette smoke exposure exacerbates lung inflammation and compromises immunity to bacterial infection," The Journal of Immunology, vol. 192, no. 11, pp. 5226-5235, 2014.

[152] G. G. Brusselle, G. F. Joos, and K. R. Bracke, "New insights into the immunology of chronic obstructive pulmonary disease," The Lancet, vol. 378, no. 9795, pp. 1015-1026, 2011.

[153] T. A. Bhat, L. Panzica, S. G. Kalathil, and Y. Thanavala, "Immune dysfunction in patients with chronic obstructive pulmonary disease," Annals of the American Thoracic Society, vol. 12, Supplement 2, pp. S169-S175, 2015.

[154] T. Maes, K. R. Bracke, K. Y. Vermaelen et al., "Murine TLR4 is implicated in cigarette smoke-induced pulmonary inflammation," International Archives of Allergy and Immunology, vol. 141, no. 4, pp. 354-368, 2006.

[155] N. Ferhani, S. Letuve, A. Kozhich et al., "Expression of highmobility group box 1 and of receptor for advanced glycation end products in chronic obstructive pulmonary disease," American Journal of Respiratory and Critical Care Medicine, vol. 181, no. 9, pp. 917-927, 2010.

[156] M. Lommatzsch, S. Cicko, T. Müller et al., "Extracellular adenosine triphosphate and chronic obstructive pulmonary disease," American Journal of Respiratory and Critical Care Medicine, vol. 181, no. 9, pp. 928-934, 2010.

[157] R. Y. Kim, J. W. Pinkerton, P. G. Gibson, M. A. Cooper, J. C. Horvat, and P. M. Hansbro, "Inflammasomes in COPD and neutrophilic asthma," Thorax, vol. 70, no. 12, pp. 11991201, 2015.

[158] P. J. Barnes, "Inflammatory mechanisms in patients with chronic obstructive pulmonary disease," Journal of Allergy and Clinical Immunology, vol. 138, no. 1, pp. 16-27, 2016.

[159] A. Churg, S. Zhou, X. Wang, R. Wang, and J. L. Wright, “The role of interleukin- $1 \beta$ in murine cigarette smoke-induced emphysema and small airway remodeling," American Journal of Respiratory Cell and Molecular Biology, vol. 40, no. 4, pp. 482-490, 2009.

[160] C. Schulz, K. Wolf, M. Harth, K. Krätzel, L. Kunz-Schughart, and M. Pfeifer, "Expression and release of interleukin- 8 by human bronchial epithelial cells from patients with chronic obstructive pulmonary disease, smokers, and neversmokers," Respiration, vol. 70, no. 3, pp. 254-261, 2003.

[161] E. F. A. van 't Wout, J. A. Dickens, A. van Schadewijk et al., "Increased ERK signalling promotes inflammatory signalling in primary airway epithelial cells expressing $\mathrm{Z} \alpha 1$-antitrypsin," Human Molecular Genetics, vol. 23, no. 4, pp. 929941, 2014.

[162] A. Di Stefano, G. Caramori, I. Gnemmi et al., "T helper type 17-related cytokine expression is increased in the bronchial mucosa of stable chronic obstructive pulmonary disease patients," Clinical \& Experimental Immunology, vol. 157, no. 2, pp. 316-324, 2009.

[163] C. Doe, M. Bafadhel, S. Siddiqui et al., "Expression of the T helper 17-associated cytokines IL-17A and IL-17F in asthma and COPD," Chest, vol. 138, no. 5, pp. 1140-1147, 2010.

[164] E. Sapey, J. A. Stockley, H. Greenwood et al., "Behavioral and structural differences in migrating peripheral neutrophils from patients with chronic obstructive pulmonary disease," American Journal of Respiratory and Critical Care Medicine, vol. 183, no. 9, pp. 1176-1186, 2011.

[165] C. S. Berenson, M. A. Garlipp, L. J. Grove, J. Maloney, and S. Sethi, "Impaired phagocytosis of nontypeable Haemophilus influenzae by human alveolar macrophages in chronic obstructive pulmonary disease," The Journal of Infectious Diseases, vol. 194, no. 10, pp. 1375-1384, 2006.

[166] C. S. Berenson, C. T. Wrona, L. J. Grove et al., "Impaired alveolar macrophage response to Haemophilus antigens in chronic obstructive lung disease," American Journal of Respiratory and Critical Care Medicine, vol. 174, no. 1, pp. 31-40, 2006.

[167] A. E. Taylor, T. K. Finney-Hayward, J. K. Quint et al., "Defective macrophage phagocytosis of bacteria in COPD," European Respiratory Journal, vol. 35, no. 5, pp. 1039-1047, 2010.

[168] C. S. Berenson, R. L. Kruzel, E. Eberhardt et al., "Impaired innate immune alveolar macrophage response and the predilection for COPD exacerbations," Thorax, vol. 69, no. 9, pp. 811-818, 2014.

[169] G. R. Van Pottelberge, K. R. Bracke, I. K. Demedts et al., "Selective accumulation of Langerhans-type dendritic cells in small airways of patients with COPD," Respiratory Research, vol. 11, no. 1, p. 35, 2010.

[170] C. M. Freeman, F. J. Martinez, M. L. K. Han et al., "Lung dendritic cell expression of maturation molecules increases with worsening chronic obstructive pulmonary disease," American Journal of Respiratory and Critical Care Medicine, vol. 180, no. 12, pp. 1179-1188, 2009.

[171] R. Vassallo, P. R. Walters, J. Lamont, T. J. Kottom, E. S. Yi, and A. H. Limper, "Cigarette smoke promotes dendritic cell accumulation in COPD; a lung tissue research consortium study," Respiratory Research, vol. 11, no. 1, p. 45, 2010.

[172] I. K. Demedts, K. R. Bracke, G. Van Pottelberge et al., "Accumulation of dendritic cells and increased CCL20 levels in the airways of patients with chronic obstructive pulmonary disease," American Journal of Respiratory and Critical Care Medicine, vol. 175, no. 10, pp. 998-1005, 2007.

[173] A. V. Rogers, E. Adelroth, K. Hattotuwa, A. Dewar, and P. K. Jeffery, "Bronchial mucosal dendritic cells in smokers and exsmokers with COPD: an electron microscopic study," Thorax, vol. 63, no. 2, pp. 108-114, 2008.

[174] M. Tsoumakidou, I. Bouloukaki, H. Koutala et al., "Decreased sputum mature dendritic cells in healthy smokers and patients with chronic obstructive pulmonary disease," International Archives of Allergy and Immunology, vol. 150, no. 4, pp. 389-397, 2009.

[175] S.-X. Liao, T. Ding, X.-M. Rao et al., "Cigarette smoke affects dendritic cell maturation in the small airways of patients with chronic obstructive pulmonary disease," Molecular Medicine Reports, vol. 11, no. 1, pp. 219-225, 2015.

[176] J. Mjösberg and H. Spits, "Human innate lymphoid cells," Journal of Allergy and Clinical Immunology, vol. 138, no. 5, pp. 1265-1276, 2016. 
[177] K. C. De Grove, S. Provoost, F. M. Verhamme et al., "Characterization and quantification of innate lymphoid cell subsets in human lung," PLoS One, vol. 11, no. 1, p. e0145961, 2016.

[178] J. S. Silver, J. Kearley, A. M. Copenhaver et al., "Inflammatory triggers associated with exacerbations of COPD orchestrate plasticity of group 2 innate lymphoid cells in the lungs," Nature Immunology, vol. 17, no. 6, pp. 626-635, 2016.

[179] S. M. Bal, J. H. Bernink, M. Nagasawa et al., "IL-1 $\beta$, IL-4 and IL-12 control the fate of group 2 innate lymphoid cells in human airway inflammation in the lungs," Nature Immunology, vol. 17, no. 6, pp. 636-645, 2016.

[180] A. B. Roos, C. Sandén, M. Mori, L. Bjermer, M. R. Stampfli, and J. S. Erjefält, "IL-17A is elevated in end-stage chronic obstructive pulmonary disease and contributes to cigarette smokeinduced lymphoid neogenesis," American Journal of Respiratory and Critical Care Medicine, vol. 191, no. 11, pp. 1232-1241, 2015.

[181] E. Montaldo, K. Juelke, and C. Romagnani, “Group 3 innate lymphoid cells (ILC3s): origin, differentiation, and plasticity in humans and mice," European Journal of Immunology, vol. 45 , no. 8 , pp. 2171-2182, 2015.

[182] J. C. Hogg, F. Chu, S. Utokaparch et al., "The nature of small-airway obstruction in chronic obstructive pulmonary disease," New England Journal of Medicine, vol. 350, no. 26, pp. 2645-2653, 2004.

[183] B. W. A. van der Strate, D. S. Postma, C.-A. Brandsma et al., "Cigarette smoke-induced emphysema: a role for the B cell?," American Journal of Respiratory and Critical Care Medicine, vol. 173, no. 7, pp. 751-758, 2006.

[184] M. Mori, C. K. Andersson, K. A. Svedberg et al., "Appearance of remodelled and dendritic cell-rich alveolar-lymphoid interfaces provides a structural basis for increased alveolar antigen uptake in chronic obstructive pulmonary disease," Thorax, vol. 68, no. 6, pp. 521-531, 2013.

[185] E. J. Lammertyn, E. Vandermeulen, H. Bellon et al., "Endstage cystic fibrosis lung disease is characterised by a diverse inflammatory pattern: an immunohistochemical analysis," Respiratory Research, vol. 18, no. 1, p. 10, 2017.

[186] J. Frija-Masson, C. Martin, L. Regard et al., "Bacteria-driven peribronchial lymphoid neogenesis in bronchiectasis and cystic fibrosis," European Respiratory Journal, vol. 49, no. 4, p. 1601873, 2017.

[187] J. A. Voynow, B. M. Fischer, B. C. Roberts, and A. D. Proia, "Basal-like cells constitute the proliferating cell population in cystic fibrosis airways," American Journal of Respiratory and Critical Care Medicine, vol. 172, no. 8, pp. 1013-8, 2005.

[188] N. T. N. Trinh, O. Bardou, A. Privé et al., "Improvement of defective cystic fibrosis airway epithelial wound repair after CFTR rescue," European Respiratory Journal, vol. 40, no. 6, pp. 1390-1400, 2012.

[189] C. Hubeau, M. Lorenzato, J. P. Couetil et al., "Quantitative analysis of inflammatory cells infiltrating the cystic fibrosis airway mucosa," Clinical and Experimental Immunology, vol. 124, no. 1, pp. 69-76, 2001.

[190] M. W. Leigh, J. E. Kylander, J. R. Yankaskas, and R. C. Boucher, "Cell proliferation in bronchial epithelium and submucosal glands of cystic fibrosis patients," American Journal of Respiratory Cell and Molecular Biology, vol. 12, no. 6, pp. 605-612, 1995.
[191] T. Piorunek, A. Marszalek, W. Biczysko, J. Gozdzik, S. Cofta, and M. Seget, "Correlation between the stage of cystic fibrosis and the level of morphological changes in adult patients," Journal of Physiology and Pharmacology, vol. 59, Supplement 6, pp. 565-572, 2008.

[192] H. A. Tiddens, L. P. Koopman, R. K. Lambert et al., "Cartilaginous airway wall dimensions and airway resistance in cystic fibrosis lungs," European Respiratory Journal, vol. 15, no. 4, pp. 735-742, 2000.

[193] M. Dovey, C. L. Wisseman, V. L. Roggli, G. M. Roomans, J. D. Shelburne, and A. Spock, "Ultrastructural morphology of the lung in cystic fibrosis," Journal of Submicroscopic Cytology and Pathology, vol. 21, no. 3, pp. 521-534, 1989.

[194] H. Gilljam, A. M. Motakefi, B. Robertson, and B. Strandvik, "Ultrastructure of the bronchial epithelium in adult patients with cystic fibrosis," European Journal of Respiratory Diseases, vol. 71, no. 3, pp. 187-194, 1987.

[195] E. H. Oppenheimer, "Similarity of the tracheobronchial mucous glands and epithelium in infants with and without cystic fibrosis," Human Pathology, vol. 12, no. 1, pp. 36-48, 1981.

[196] R. W. A. Godfrey, N. J. Severs, and P. K. Jeffery, "Structural alterations of airway epithelial tight junctions in cystic fibrosis: comparison of transplant and postmortem tissue," American Journal of Respiratory Cell and Molecular Biology, vol. 9, no. 2, pp. 148-156, 1993.

[197] H. A. W. M. Tiddens, S. H. Donaldson, M. Rosenfeld, and P. D. Paré, "Cystic fibrosis lung disease starts in the small airways: can we treat it more effectively?," Pediatric Pulmonology, vol. 45, no. 2, pp. 107-117, 2010.

[198] I. Durieu, S. Peyrol, D. Gindre, G. Bellon, D. V. Durand, and Y. Pacheco, "Subepithelial fibrosis and degradation of the bronchial extracellular matrix in cystic fibrosis," American Journal of Respiratory and Critical Care Medicine, vol. 158, no. 2, pp. 580-588, 1998.

[199] S. R. Hays and J. V. Fahy, "Characterizing mucous cell remodeling in cystic fibrosis: relationship to neutrophils," American Journal of Respiratory and Critical Care Medicine, vol. 174, no. 9, pp. 1018-1024, 2006.

[200] K. R. Schiller, P. J. Maniak, and S. M. O'Grady, "Cystic fibrosis transmembrane conductance regulator is involved in airway epithelial wound repair," American Journal of Physiology-Cell Physiology, vol. 299, no. 5, pp. C912-C921, 2010.

[201] M. O. Wielpütz, O. Weinheimer, M. Eichinger et al., "Pulmonary emphysema in cystic fibrosis detected by densitometry on chest multidetector computed tomography," PLoS One, vol. 8, no. 8, article e73142, 2013.

[202] O. M. Mets, S. M. Roothaan, I. Bronsveld et al., "Emphysema is common in lungs of cystic fibrosis lung transplantation patients: a histopathological and computed tomography study," PLoS One, vol. 10, no. 6, article e0128062, 2015.

[203] I. Petrache, V. Natarajan, L. Zhen et al., "Ceramide upregulation causes pulmonary cell apoptosis and emphysema-like disease in mice," Nature Medicine, vol. 11, no. 5, pp. 491498, 2005.

[204] K. L. Kirk, "CFTR channels and wound healing. Focus on "cystic fibrosis transmembrane conductance regulator is involved in airway epithelial wound repair"," American Journal of Physiology-Cell Physiology, vol. 299, no. 5, pp. C888-C890, 2010. 
[205] N. T. N. Trinh, A. Privé, E. Maillé, J. Noël, and E. Brochiero, "EGF and $\mathrm{K}^{+}$channel activity control normal and cystic fibrosis bronchial epithelia repair," American Journal of Physiology-Lung Cellular and Molecular Physiology, vol. 295, no. 5, pp. L866-L880, 2008.

[206] C. M. Gosden and J. R. Gosden, "Fetal abnormalities in cystic fibrosis suggest a deficiency in proteolysis of cholecystokinin," The Lancet, vol. 324, no. 8402, pp. 541-546, 1984.

[207] A. Ornoy, J. Arnon, D. Katznelson et al., "Pathological confirmation of cystic fibrosis in the fetus following prenatal diagnosis," American Journal of Medical Genetics, vol. 28, no. 4, pp. 935-947, 1987.

[208] R. Hajj, P. Lesimple, B. Nawrocki-Raby, P. Birembaut, E. Puchelle, and C. Coraux, "Human airway surface epithelial regeneration is delayed and abnormal in cystic fibrosis," The Journal of Pathology, vol. 211, no. 3, pp. 340-350, 2007.

[209] D. Adam, J. Roux-Delrieu, E. Luczka et al., "Cystic fibrosis airway epithelium remodelling: involvement of inflammation," The Journal of Pathology, vol. 235, no. 3, pp. 408-419, 2015.

[210] I. Vachier, A. M. Vignola, G. Chiappara et al., "Inflammatory features of nasal mucosa in smokers with and without COPD," Thorax, vol. 59, no. 4, pp. 303-307, 2004.

[211] P. K. Jeffery, "Comparison of the structural and inflammatory features of COPD and asthma Giles F. Filley lecture," Chest, vol. 117, no. 5, pp. 251S-260S, 2000.

[212] J. F. Chmiel and M. W. Konstan, "Inflammation and antiinflammatory therapies for cystic fibrosis," Clinics in Chest Medicine, vol. 28, no. 2, pp. 331-346, 2007.

[213] T. N. Hilliard, N. Regamey, J. K. Shute et al., "Airway remodelling in children with cystic fibrosis,” Thorax, vol. 62, no. 12, pp. 1074-1080, 2007.

[214] M. C. Bruce, L. Poncz, J. D. Klinger, R. C. Stern, Tomashefski JF Jr, and D. G. Dearborn, "Biochemical and pathologic evidence for proteolytic destruction of lung connective tissue in cystic fibrosis," American Review of Respiratory Disease, vol. 132, no. 3, pp. 529-535, 1985.

[215] N. Regamey, P. K. Jeffery, E. W. F. W. Alton, A. Bush, and J. C. Davies, "Airway remodelling and its relationship to inflammation in cystic fibrosis," Thorax, vol. 66, no. 7, pp. 624-629, 2011.

[216] T. Iosifidis, L. W. Garratt, D. R. Coombe, D. A. Knight, S. M. Stick, and A. Kicic, "Airway epithelial repair in health and disease: orchestrator or simply a player?," Respirology, vol. 21, no. 3, pp. 438-448, 2016.

[217] L. W. Garratt, E. N. Sutanto, K. M. Ling et al., "Alpha-1 antitrypsin mitigates the inhibition of airway epithelial cell repair by neutrophil elastase," American Journal of Respiratory Cell and Molecular Biology, vol. 54, no. 3, pp. 341-349, 2016.

[218] A. Gaggar, A. Hector, P. E. Bratcher, M. A. Mall, M. Griese, and D. Hartl, "The role of matrix metalloproteinases in cystic fibrosis lung disease," European Respiratory Journal, vol. 38, no. 3, pp. 721-727, 2011.

[219] S. D. Sagel, R. K. Kapsner, and I. Osberg, "Induced sputum matrix metalloproteinase-9 correlates with lung function and airway inflammation in children with cystic fibrosis," Pediatric Pulmonology, vol. 39, no. 3, pp. 224-232, 2005.

[220] L. W. Garratt, E. N. Sutanto, K.-M. Ling et al., "Matrix metalloproteinase activation by free neutrophil elastase contributes to bronchiectasis progression in early cystic fibrosis," European Respiratory Journal, vol. 46, no. 2, pp. 384-394, 2015.

[221] U. I. Sires, G. Murphy, V. M. Baragi, C. J. Fliszar, H. G. Welgus, and R. M. Senior, "Matrilysin is much more efficient than other matrix metalloproteinases in the proteolytic inactivation of $\alpha_{1}$-antitrypsin," Biochemical and Biophysical Research Communications, vol. 204, no. 2, pp. 613-620, 1994.

[222] J. R. Peters-Hall, K. J. Brown, D. K. Pillai et al., "Quantitative proteomics reveals an altered cystic fibrosis in vitro bronchial epithelial secretome," American Journal of Respiratory Cell and Molecular Biology, vol. 53, no. 1, pp. 22-32, 2015.

[223] Y. Itokazu, R. E. Pagano, A. S. Schroeder, S. M. O'Grady, A. H. Limper, and D. L. Marks, "Reduced GM1 ganglioside in CFTR-deficient human airway cells results in decreased $\beta_{1}$-integrin signaling and delayed wound repair," American Journal of Physiology-Cell Physiology, vol. 306, no. 9, pp. C819-C830, 2014.

[224] R. E. Sobonya and L. M. Taussig, "Quantitative aspects of lung pathology in cystic fibrosis," American Review of Respiratory Disease, vol. 134, no. 2, pp. 290-295, 1986.

[225] R. Hamutcu, J. M. Rowland, M. V. Horn et al., "Clinical findings and lung pathology in children with cystic fibrosis," American Journal of Respiratory and Critical Care Medicine, vol. 165, no. 8, pp. 1172-1175, 2002.

[226] M. Boon, S. E. Verleden, B. Bosch et al., "Morphometric analysis of explant lungs in cystic fibrosis," American Journal of Respiratory and Critical Care Medicine, vol. 193, no. 5, pp. 516-526, 2016.

[227] M. Saetta, G. Turato, S. Baraldo et al., "Goblet cell hyperplasia and epithelial inflammation in peripheral airways of smokers with both symptoms of chronic bronchitis and chronic airflow limitation," American Journal of Respiratory and Critical Care Medicine, vol. 161, no. 3, pp. 1016-1021, 2000.

[228] J. E. McDonough, R. Yuan, M. Suzuki et al., "Small-airway obstruction and emphysema in chronic obstructive pulmonary disease," New England Journal of Medicine, vol. 365, no. 17, pp. 1567-1575, 2011.

[229] J. Yang, W. L. Zuo, T. Fukui et al., "Smoking-dependent distal-to-proximal repatterning of the adult human small airway epithelium," American Journal of Respiratory and Critical Care Medicine, vol. 196, no. 3, pp. 340-352, 2017.

[230] W. I. de Boer, C. M. Hau, A. van Schadewijk, J. Stolk, J. H. J. M. van Krieken, and P. S. Hiemstra, "Expression of epidermal growth factors and their receptors in the bronchial epithelium of subjects with chronic obstructive pulmonary disease," American Journal of Clinical Pathology, vol. 125, no. 2, pp. 184-192, 2006.

[231] J. M. Perotin, D. Adam, J. Vella-Boucaud et al., "Delay of airway epithelial wound repair in COPD is associated with airflow obstruction severity," Respiratory Research, vol. 15, no. 1, p. 151, 2014.

[232] S. S. Sohal, D. Reid, A. Soltani et al., "Evaluation of epithelial mesenchymal transition in patients with chronic obstructive pulmonary disease," Respiratory Research, vol. 12, no. 1, p. $130,2011$.

[233] C. Hupin, S. Gohy, C. Bouzin, M. Lecocq, M. Polette, and C. Pilette, "Features of mesenchymal transition in the airway epithelium from chronic rhinosinusitis," Allergy, vol. 69, no. 11, pp. 1540-1549, 2014.

[234] H. W. Shin, K. Cho, D. W. Kim et al., "Hypoxia-inducible factor 1 mediates nasal polypogenesis by inducing epithelial-to- 
mesenchymal transition," American Journal of Respiratory and Critical Care Medicine, vol. 185, no. 9, pp. 944-954, 2012.

[235] M. Mahmood, S. S. Sohal, S. D. Shukla et al., "Epithelial mesenchymal transition in smokers: large versus small airways and relation to airflow obstruction," International Journal of Chronic Obstructive Pulmonary Disease, vol. 10, pp. 1515-1524, 2015.

[236] J. Milara, T. Peiró, A. Serrano, and J. Cortijo, "Epithelial to mesenchymal transition is increased in patients with COPD and induced by cigarette smoke," Thorax, vol. 68, no. 5, pp. 410-420, 2013.

[237] S. T. Gohy, C. Hupin, C. Fregimilicka et al., "Imprinting of the COPD airway epithelium for dedifferentiation and mesenchymal transition," European Respiratory Journal, vol. 45, no. 5, pp. 1258-1272, 2015.

[238] I. H. Heijink, H. G. de Bruin, R. Dennebos et al., "Cigarette smoke-induced epithelial expression of WNT-5B: implications for COPD," European Respiratory Journal, vol. 48, no. 2, pp. 504-515, 2016.

[239] H. A. Baarsma, W. Skronska-Wasek, K. Mutze et al., "Noncanonical WNT-5A signaling impairs endogenous lung repair in COPD," The Journal of Experimental Medicine, vol. 214, no. 1, pp. 143-163, 2017.

[240] S. T. Gohy, B. R. Detry, M. Lecocq et al., "Polymeric immunoglobulin receptor down-regulation in chronic obstructive pulmonary disease. Persistence in the cultured epithelium and role of transforming growth factor- $\beta$," American Journal of Respiratory and Critical Care Medicine, vol. 190, no. 5, pp. 509-521, 2014.

[241] C. Pilette, V. Godding, R. Kiss et al., "Reduced epithelial expression of secretory component in small airways correlates with airflow obstruction in chronic obstructive pulmonary disease," American Journal of Respiratory and Critical Care Medicine, vol. 163, no. 1, pp. 185-194, 2001.

[242] B. W. Richmond, R. M. Brucker, W. Han et al., "Airway bacteria drive a progressive COPD-like phenotype in mice with polymeric immunoglobulin receptor deficiency," Nature Communications, vol. 7, article 11240, 2016.

[243] S. S. Sohal, A. Soltani, D. Reid et al., "A randomized controlled trial of inhaled corticosteroids (ICS) on markers of epithelial-mesenchymal transition (EMT) in large airway samples in COPD: an exploratory proof of concept study," International Journal of Chronic Obstructive Pulmonary Disease, vol. 9, pp. 533-542, 2014.

[244] M. Podowski, C. Calvi, S. Metzger et al., “Angiotensin receptor blockade attenuates cigarette smoke-induced lung injury and rescues lung architecture in mice," Journal of Clinical Investigation, vol. 122, no. 1, pp. 229-240, 2012. 


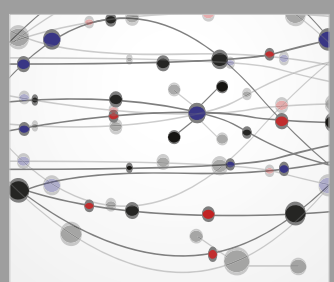

The Scientific World Journal
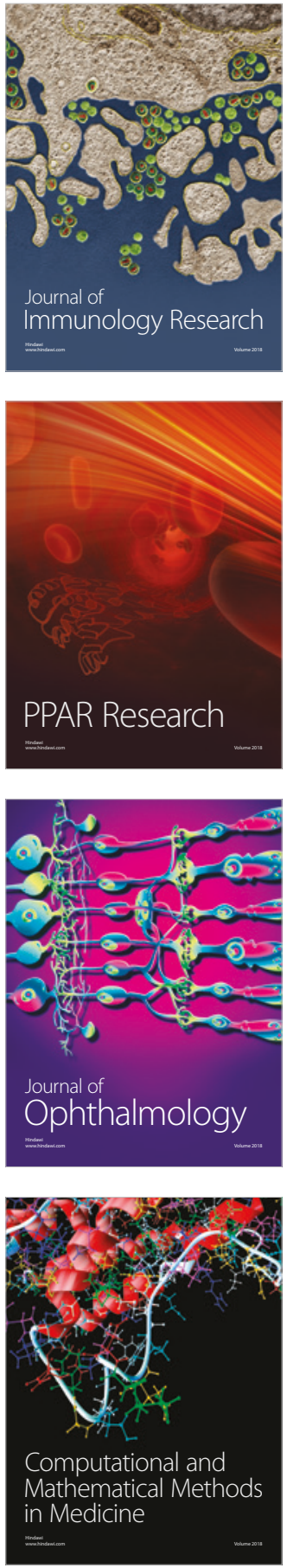

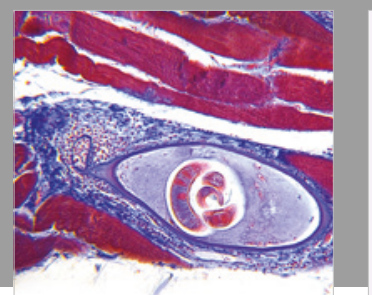

Gastroenterology Research and Practice

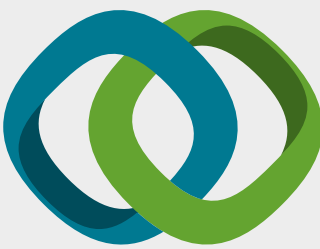

\section{Hindawi}

Submit your manuscripts at

www.hindawi.com
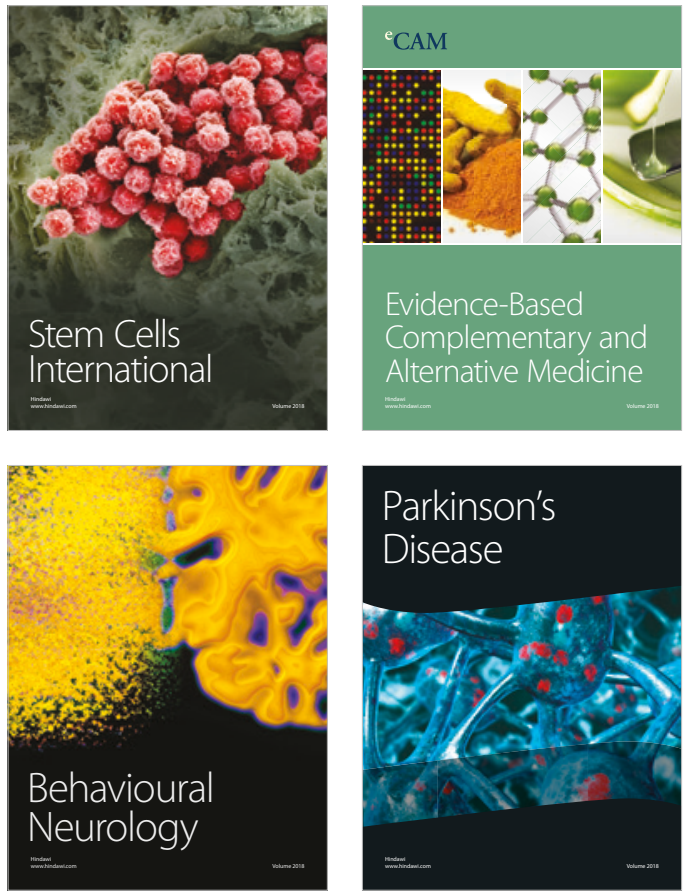

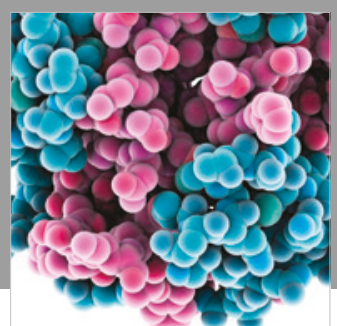

ournal of

Diabetes Research

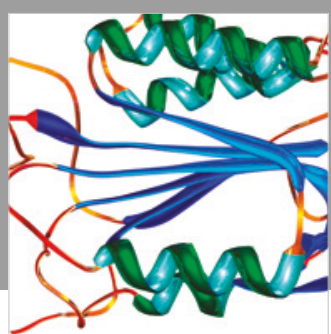

Disease Markers
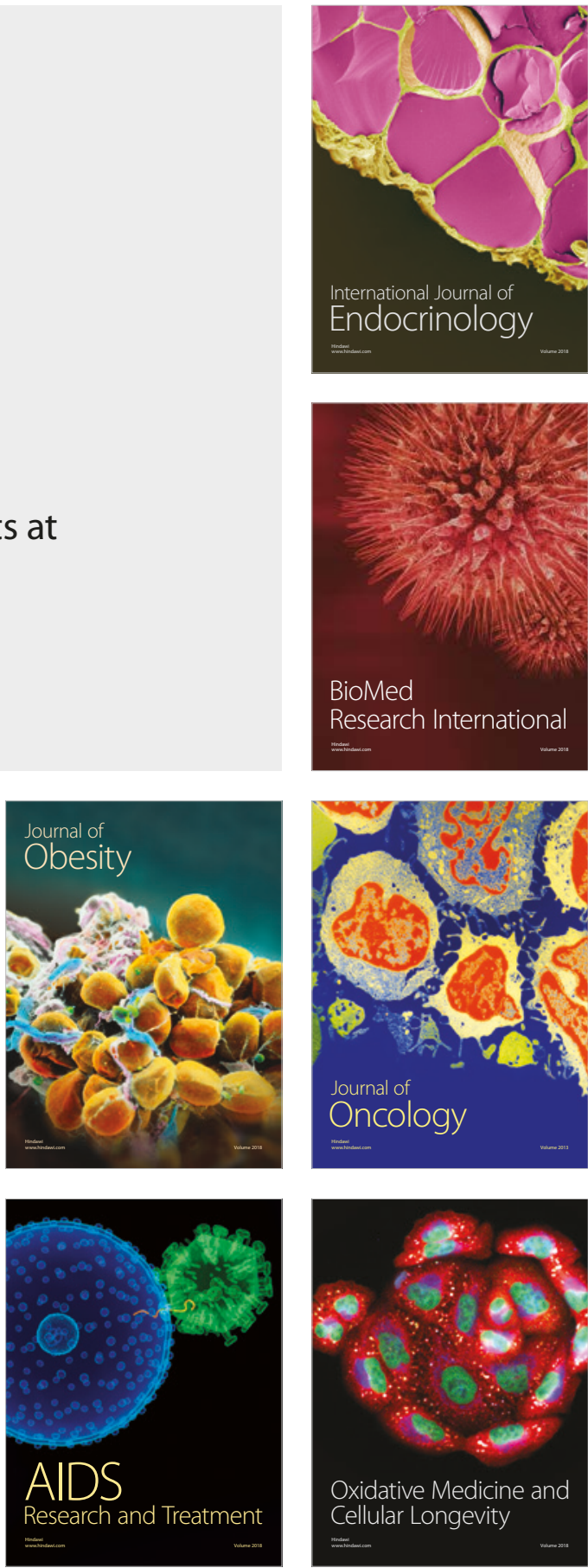